\title{
Comparing the Clinical Utility and Diagnostic Performance of CSF P-Tau181, P-Tau217, and P-Tau231 Assays
}

Antoine Leuzy, PhD, Shorena Janelidze, PhD, Niklas Mattsson-Carlgren, MD, PhD, Sebastian Palmqvist, MD, PhD, Dirk Jacobs, PhD, Claudia Cicognola, MD, PhD, Erik Stomrud, MD, PhD, Eugeen Vanmechelen, PhD, Jeffrey L. Dage, PhD, and Oskar Hansson, MD, PhD

Neurology ${ }^{\circledR}$ 2021;97:e1681-e1694. doi:10.1212/WNL.0000000000012727

\section{Abstract}

\section{Background and Objectives}

Phosphorylated tau (p-tau) in CSF is considered an important biomarker in Alzheimer disease (AD) and has been incorporated in recent diagnostic criteria. Several variants exist, including p-tau at threonines 181 (p-tau181), 217 (p-tau217), and 231 (p-tau231). However, no studies have compared their diagnostic performance or association to $\beta$-amyloid $(\mathrm{A} \beta)$ and tau-PET. Understanding which p-tau variant to use remains an important yet answered question. We aimed to compare the diagnostic accuracy of p-tau181, p-tau217, and p-tau231 in CSF for AD and their association with A $\beta$ and tau-PET.

\section{Methods}

A total of 629 participants in the Swedish BioFINDER-2 study were included (cognitively unimpaired, $\mathrm{n}=334$; $\mathrm{A} \beta$-positive mild cognitive impairment, $\mathrm{n}=84$; $\mathrm{AD}$ dementia, $\mathrm{n}=119$; and non- $\mathrm{AD}$ disorders, $\mathrm{n}=92$ ). In addition to $\mathrm{p}$-tau 181 and $\mathrm{p}$-tau 217 measured using assays with the same detector antibodies from Eli Lilly (p-tau181 $1_{\text {Lilly, }}$ p-tau217 $7_{\text {Lilly }}$ ) and p-tau231, we also included p-tau181 measurements from 2 commonly used assays (Innotest and Elecsys).

\section{Results}

Although all p-tau variants increased across the $\mathrm{AD}$ continuum, $\mathrm{p}$-tau217 Lilly $_{\text {showed the }}$ greatest dynamic range (13-fold increase vs 1.9-5.4-fold increase for other $\mathrm{p}$-tau variants for $\mathrm{AD}$

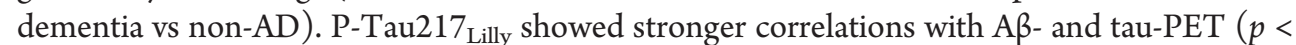
0.0001). P-Tau217 Lilly exhibited higher accuracy than other $p$-tau variants for separating $\mathrm{AD}$ dementia from non-AD (area under the curve [AUC], 0.98 vs $0.88[p<0.0001]-0.96[p<$ $0.05]$ ) and for identifying A $\beta$-PET (AUC, 0.86 vs $0.74[p<0.0001]$ and $0.83[p<0.001]$ ) and tau-PET positivity (AUC, 0.94 vs $0.80-0.92, p<0.0001$ ). Finally, $\mathrm{p}$-Tau $181_{\text {Lilly }}$ generally performed better than the other p-tau 181 assays (e.g., $\mathrm{AD}$ dementia vs non-AD, AUC, 0.96 vs $0.88\left[\mathrm{p}\right.$-tau $\left.181_{\text {Innotest }}\right]$ and $0.89\left[\mathrm{p}\right.$-tau $\left.\left.181_{\text {Elecsys }}\right] ; p<0.0001\right)$.

\section{Discussion}

CSF p-tau217 $7_{\text {Lilly }}$ seems to be more useful than other included p-tau assays in the workup of $\mathrm{AD}$. Varied results across p-tau181 assays highlights the importance of anti-tau antibodies for biomarker performance.

\section{Classification of Evidence}

This study provides Class II evidence that $\mathrm{p}$-tau217 provides higher diagnostic accuracy for diagnosis of $\mathrm{AD}$ dementia than p-tau181 or p-tau231.

\author{
Correspondence \\ Dr. Leuzy \\ antoine.leuzy@med.lu.se \\ or Dr. Hansson \\ oskar.hansson@med.lu.se
}

\section{MORE ONLINE}

(II) Class of Evidence

Criteria for rating

therapeutic and diagnostic studies

NPub.org/coe 


\section{Glossary}

$\mathbf{A} \boldsymbol{\beta}=\beta$-amyloid $\mathbf{A D}=$ Alzheimer disease $; \mathbf{A U C}=$ area under the receiver operating characteristic curve; $\mathbf{C B S}=$ corticobasal syndrome; CI = confidence interval; CU = cognitively unimpaired; DSM-5 = Diagnostic and Statistical Manual of Mental Disorders, 5th edition; FTD = frontotemporal dementia; $\mathbf{M C I}=$ mild cognitive impairment; $\mathbf{M S D}=$ Meso Scale Discovery; NFT = neurofibrillary tangle; $\mathbf{p}$-tau $=$ phosphorylated tau; $\mathbf{p}$-tau181 $=$ tau phosphorylated at threonine-181; $\mathbf{p}$-tau217 = tau phosphorylated at threonine-217; $\mathbf{p}$-tau231 = tau phosphorylated at threonine-231; PD = Parkinson disease; PSP = progressive supranuclear palsy; PTM = post-translational modification; $\mathbf{R O C}=$ receiver operating characteristic; $\mathbf{R O I}=$ region of interest; SUVR = standardized uptake value ratio; $\mathrm{VaD}=$ vascular dementia.

In addition to extracellular deposition of $\beta$-amyloid $(A \beta)$ plaques, Alzheimer disease $(\mathrm{AD})$ is defined by the intracellular aggregation of tau in neurofibrillary tangles (NFTs), composed of abnormally hyperphosphorylated tau. ${ }^{1}$ Tau pathology is thought to be reflected in CSF levels of phosphorylated tau ( $\mathrm{p}$ tau). CSF p-tau has shown high prognostic accuracy for $\mathrm{AD}$ and for predicting cognitive decline in cognitively unimpaired (CU) individuals and in patients with mild cognitive impairment (MCI) due to $\mathrm{AD}^{2,3}$ As CSF p-tau levels are higher in $\mathrm{AD}$ compared to other non- $\mathrm{AD}$ neurodegenerative disorders, including progressive supranuclear palsy (PSP), corticobasal syndrome (CBS), frontotemporal dementia (FTD), and vascular dementia $(\mathrm{VaD})$, it has also proven of use in the differential diagnosis of $\mathrm{AD}$ vs other dementias. ${ }^{4}$

Tau in CSF is largely present in the form of different fragments. ${ }^{5-8}$ Of these, $\mathrm{N}$-terminal and midregion variants are the most abundant. In addition, numerous sites exist where tau can undergo abnormal hyperphosphorylation. ${ }^{9}$ The most commonly used assays for p-tau, however, use antibodies targeting the midregion of tau as well as an antibody targeting tau phosphorylated at threonine-181 (p-tau181). ${ }^{10}$ Besides $\mathrm{p}$-tau181, increased levels of mid tau fragments phosphorylated at threonine-231 ( $\mathrm{p}$-tau231) appear to be an early occurrence in $\mathrm{AD}$, preceding the formation of paired helical filaments. ${ }^{11} \mathrm{Al}-$ though studies have shown that p-tau231 can accurately discriminate patients with $\mathrm{AD}$ from $\mathrm{CU}$ individuals and patients with non- $\mathrm{AD}$ disorders, similar to $\mathrm{p}$-tau181, a series of postmortem studies that examined both measures reported that CSF p-tau231 was better associated with neocortical fibrillary pathology than CSF p-tau181. ${ }^{12,13}$ Recently, p-tau fragments phosphorylated at threonine-217 ( $\mathrm{p}$-tau217) were also measured in CSF. ${ }^{14}$ Compared to p-tau181, p-tau217 showed stronger correlations with $\mathrm{A} \beta$ and tau-PET and more accurately distinguished $\mathrm{AD}$ dementia from non- $\mathrm{AD}$ neurodegenerative disorders. ${ }^{14}$ Additional work has shown that $\mathrm{p}$-tau181 and p-tau217 are increased already in preclinical $\mathrm{AD}$ (A $\beta$-positive $\mathrm{CU})$, with these increases preceding tau-PET positivity and even occurring prior to the threshold for A $\beta$-PET positivity. ${ }^{15,16}$

Overall, findings indicate that increases in CSF p-tau occur in response to very early $A \beta$ pathology and precede widespread tau aggregation. Thus far, however, there are no studies comparing $\mathrm{p}$-tau181, $\mathrm{p}$-tau217, and $\mathrm{p}$-tau231 levels in relation to $\mathrm{A} \beta$ and tau-PET across the symptomatic stages of $\mathrm{AD}$, nor data directly comparing their diagnostic performance for separating $\mathrm{AD}$ dementia from non- $\mathrm{AD}$ neurodegenerative disorders and for identifying abnormal $A \beta$ and tau-PET status. Because CSF $\mathrm{p}$-tau is an important biomarker in the workup for $\mathrm{AD}$ and is incorporated in its diagnostic criteria, ${ }^{17}$ it is of great importance to determine which of these p-tau variants to use, especially as clinical heterogeneity and different stages in $\mathrm{AD}$ may be determined by heterogeneity in the post-translational modification (PTM) of tau. ${ }^{18}$

We aimed to address these questions using cross-sectional data from a well-characterized cohort, ranging from $A \beta$-negative $C U$ individuals to $A \beta$-positive $C U$ individuals and $A \beta$ positive patients with $\mathrm{MCI}$ or $\mathrm{AD}$ dementia. In addition to comparing p-tau181 and p-tau 217 measured using assays with the same detector antibodies from Eli Lilly (p-tau $181_{\text {Lilly }}$ and p-tau217 Lilly) with p-tau231 measured using an assay with a phospho-specific cis-conformational monoclonal antibody (p-tau231 $1_{\mathrm{ADx}}$ ), we also compared p-tau181 $1_{\mathrm{Lilly}}$ with p-tau181 measurements from 2 commonly used assays (Innotest [ptau $\left.181_{\text {Innotest }}\right]$ and Elecsys $\left[\mathrm{p}\right.$-tau181 $\left.\left.181_{\text {Elecsys }}\right]\right)$.

\section{Methods}

\section{Participants}

We included participants from the prospective and longitudinal Swedish BioFINDER-2 study (clinical trial NCT03174938), including $\mathrm{CU}$ participants and patients with $\mathrm{MCI}, \mathrm{AD}$ dementia, and non- $\mathrm{AD}$ neurodegenerative disorders. $\mathrm{CU}$ individuals were aged $\geq 60$ years and did not have MCI or dementia. ${ }^{17}$ Patients with MCI fulfilled DSM- 5 criteria for mild neurocognitive disorder ${ }^{19}$ and patients with $\mathrm{AD}$ dementia fulfilled the DSM- 5 criteria for major neurocognitive disorder due to $\mathrm{AD} .{ }^{19}$ Patients with non-AD disorders fulfilled diagnostic criteria for PSP or CBS, ${ }^{20,21}$ Parkinson disease (PD) with or without cognitive impairment, ${ }^{22} \mathrm{FTD},{ }^{23}$ or $\mathrm{VaD} .^{24}$ Further details pertaining to inclusion and exclusion criteria are described in the Supplement (eAppendix 1, available from Dryad, doi.org/10.5061/dryad.4f4qrfjc7). Groups were established without the use of biomarkers, but $\mathrm{CU}$ and $\mathrm{MCI}$ participants were subdivided based on $A \beta$ status, determined using CSF $\mathrm{A} \beta 42 / \mathrm{A} \beta 40$ (Innotest; Fujirebio) and a cutoff of $<0.089 .{ }^{25} \mathrm{We}$ included only $\mathrm{A} \beta$-positive $\mathrm{AD}$ dementia cases, in keeping with the research framework by the National Institute on Aging- 
Alzheimer's Association. ${ }^{17}$ As A $\beta$-PET is by design performed only in CU individuals and in patients with $\mathrm{MCI}$, CSF A 42 / $A \beta 40$ was thus chosen to have a common measure of $A \beta$ pathology across all participants.

\section{Standard Protocol Approvals, Registrations, and Patient Consents}

All participants gave written informed consent. Ethical approval was given by the Regional Ethical Committee in Lund, Sweden. Approval for PET imaging was obtained from the Swedish Medical Products Agency and the local Radiation Safety Committee at Skåne University Hospital, Sweden.

\section{CSF P-Tau181 and P-Tau217 Measurements} (Eli Lilly)

Analysis of CSF mid-domain p-tau $181_{\text {Lilly }}$ and p-tau217 1 Lilly was performed at Eli Lilly and Company using the Meso Scale Discovery (MSD) platform, as previously described. ${ }^{14}$ The anti-p-tau217 antibody IBA413 and anti-p-tau181 antibody AT270 were used as capture antibodies in the p-tau181 and p-tau217 assays, respectively. Capture antibodies were conjugated with biotin (Thermo Scientific). Sulfo-tag (MSD) conjugated LRL antibody was used as a detector in both assays. The assays were calibrated using a recombinant tau (4R2N) protein that was phosphorylated in vitro using a reaction with glycogen synthase kinase-3 and characterized by mass spectrometry. Samples were analyzed in duplicate and the mean of duplicates was used in statistical analysis. Ten samples from $A \beta$ negative CU individuals (1.59\%) were below the limit of detection and were excluded, as were 5 patients with $\mathrm{AD}$ with very high p-tau217 Lilly $_{\text {levels }}$ ( $>3$ SD above the mean).

\section{CSF P-Tau231 Measurements (ADx NeuroSciences)}

CSF p-tau231 $1_{\mathrm{ADx}}$ was measured at $\mathrm{ADx}$ NeuroSciences with a research sandwich ELISA (version 1) according to the kit instructions. Phospho-specific cis-conformational monoclonal antibody $\mathrm{ADx} 253$ (T1H11) was used as a capture antibody and biotinylated pan-tau monoclonal antibody $\mathrm{ADx} 205$ (epitope region aa224-238) as a detector. The assay was calibrated using an in-house designed synthetic peptide combining both antibody epitopes and having the corresponding threonine231 phosphorylated and proline 232 replaced by a homoproline, Pip, to reflect cis selectivity of $\mathrm{ADx} 253$. In all prior analyses, we observed a consistent low interplate variability well below $15 \%$. Because p-tau231 quantifications require $80 \mathrm{~mL}$ per single measurements-requiring at least $160 \mathrm{~mL}$ per result-we opted to run the p-tau231 measurement in singlicate as the study was designed to explore the difference between the phospho-tau assays. Quality control samples run on each plate, which were leftovers of CSF, confirmed high precision of these runs with coefficients of variation below $15 \%$.

\section{CSF P-Tau181 Measurements (Innotest and Elecsys)}

For comparative purposes, we also included p-tau181 measured using the well-known commercially available ELISA from Innotest (Fujirebio) $\left(\mathrm{p} \text {-tau181 } 1_{\text {Innotest }}\right)^{10}$ and the fully automated Elecsys electrochemiluminescence immunoassay (Roche Diagnostics) (p-tau181 $1_{\text {Elecsys }}$ ) on a cobas e601 analyzer (software version 05.02). ${ }^{26}$ For $\mathrm{p}$-tau $181_{\text {Innotest }}$ monoclonal capture/detection antibodies were HT7 (epitope region aa159-162) and AT270. For p-tau181 $1_{\text {Elecsys, }}$ a biotinylated monoclonal antibody specific for phosphorylation at threonine 181 (11H5V1) and a monoclonal tau-specific antibody (PC1C6) were used (epitope region aa195-202). All samples were analyzed at the Clinical Neurochemistry Laboratory in Mölndal, Sweden.

\section{Image Acquisition and Processing}

$\mathrm{A} \beta$ and tau-PET were performed using $\left[{ }^{18} \mathrm{~F}\right]$ flutemetamol and $\left[{ }^{18} \mathrm{~F}\right]$ RO948, respectively, as described elsewhere. ${ }^{27,28}$ Briefly, dynamic (list-mode) studies were performed over the 90- to 100-minute postinjection interval for $\left[{ }^{18} \mathrm{~F}\right]$ flutemetamol and the 70 - to 90 -minute interval for $\left[{ }^{18} \mathrm{~F}\right] \mathrm{RO} 948$. Standardized uptake value ratio (SUVR) images were created using the pons $\left(\left[{ }^{18} \mathrm{~F}\right]\right.$ flutemetamol $)$ and inferior cerebellar cortex $\left(\left[{ }^{18} \mathrm{~F}\right]\right.$ RO948) as reference regions. A high-resolution T1-weighted MRI was performed using a Siemens-3T MAGNETOM Prisma scanner for PET image coregistration and template normalization.

\section{Regions of Interest and Cutoffs}

Target regions of interest (ROIs) were chosen on the basis of previously published findings: a neocortical meta-ROI for $A \beta$ PET (prefrontal, lateral temporal, parietal, anterior cingulate, and posterior cingulate/precuneus $)^{28,29}$ and, for tau-PET, the entorhinal cortex (Braak I/II), a temporal meta-ROI (amygdala, inferior/middle temporal gyri, fusiform gyrus, and parahippocampal gyrus, approximating Braak III/IV), ${ }^{30}$ and a neocortical meta-ROI capturing late stage tau pathology (Braak V/VI). ${ }^{31}$ A priori cutoffs based on Gaussian mixture modeling $(\mathrm{A} \beta \text {-PET })^{14}$ and the mean SUVR within a given ROI plus 2.5 SDs among young $A \beta$-negative $C U$ individuals $\left(\right.$ tau-PET) ${ }^{25}$ were used to define positivity within these ROIs.

\section{Statistical Analyses}

Group differences in age-adjusted CSF p-tau levels were assessed using pairwise analysis of variance-based comparisons of linear regression models. Associations between CSF p-tau isoforms and between p-tau isoforms and ROI-based $A \beta$ and tau-PET SUVR values were assessed using correlation analysis; differences between correlation coefficients were tested using a confidence interval (CI)-based approach with bootstrapping. ${ }^{32}$ Log-transformed biomarker and PET measures were used in regression analyses. Generalized additive models with cubic regression splines were used to compare the slopes of CSF p-tau isoforms (mean change from $A \beta$-negative $C U$ ) across different tau and A $\beta$-PET SUVR values. Differences between the estimated functions were assessed by means of bootstrapped CIs. These were computed by repeatedly ( $\mathrm{n}=$ 10,000) resampling the dataset (with replacement) and calculating the differences between spline fits. The discriminative performance of CSF p-tau measures was assessed using the area 
under the receiver operating characteristic (ROC) curve (AUC), adjusted for age. Significant differences in AUC values were tested using DeLong statistics ${ }^{33}$ and Bonferroni correction was applied to account for multiple comparisons. In addition to AUC, sensitivity and specificity at the cutoff that resulted in the highest Youden index (sensitivity + specificity 1) are reported. Analyses were performed in R, v.4.0.2, with significance set at $p<0.05,2$-tailed. Voxelwise analyses examining the association between CSF p-tau levels and A $\beta$ and tauPET were performed using multilinear models, as implemented in SPM12, adjusted for age and the interval between lumbar puncture and PET scan.

\section{Data Availability}

Anonymized study data for the primary analyses presented in this report are available on request from any qualified investigator for purposes of replicating the results.

\section{Results}

\section{Participants}

We included 629 participants, including $334 \mathrm{CU}$ controls (253 [76\%] $\mathrm{A} \beta$-negative and 81 [24\%] $\mathrm{A} \beta$-positive), $84 \mathrm{~A} \beta$-positive $\mathrm{MCI}, 119 \mathrm{~A} \beta$-positive $\mathrm{AD}$ dementia, and 92 with a non-AD neurodegenerative disorder (21 FTD, 40 PD with or without cognitive impairment, $20 \mathrm{PSP} / \mathrm{CBD}$, and $11 \mathrm{VaD}$; overall, $15 \%$ $[\mathrm{n}=14]$ showed $\mathrm{A} \beta$ positivity). Demographic and clinical characteristics are summarized in Table 1. For a flow diagram of participants included in the study, see eFigure 1 (available from Dryad, doi.org/10.5061/dryad.4f4qrfjc7).

\section{Correlations Between P-Tau Isoforms}

A schematic overview of the included p-tau assays is provided in Figure 1. P-Tau isoforms were strongly correlated across all participants (range 0.853-0.977, all $p<0.0001$ ) (eFigure 2, available from Dryad, doi.org/10.5061/dryad.4f4qrfjc7). These associations were significant in $A \beta$-positive $C U, A \beta$ positive $\mathrm{MCI}$, and $\mathrm{AD}$ dementia, but not in $\mathrm{A} \beta$-negative individuals. As moderate but significant correlations were observed between age and CSF p-tau levels (eTables 1 and 2, available from Dryad, doi.org/10.5061/dryad.4f4qrfjc7), age was accounted for when comparing CSF p-tau levels across tau-PET-based Braak stages and diagnostic groups.

\section{Correlations Between CSF P-Tau and A $\beta$ and Tau-PET}

Correlations between CSF p-tau isoforms and $A \beta$ and tauPET SUVR values in Braak ROIs are reported in the Supplement (eTable 3, available from Dryad, doi.org/10.5061/ dryad.4f4qrfjc7). Correlations between the CSF p-tau species and $\mathrm{A} \beta$ or tau-PET did not differ significantly by APOE status ( $\varepsilon 4$ carrier vs noncarrier), age (over/under median split age [70 years]), or sex (male vs female) (data not shown). Using $\mathrm{A} \beta$-PET, p-tau217 Lilly $_{\text {showed the strongest correlation with }}$ neocortical SUVR values in CU individuals $(r=0.789, p<$ $0.001)$. This correlation was significantly higher than those for p-tau181 Innotest $(r=0.497)$, p-tau181 Lilly $(r=0.737)$, p-tau181 $1_{\text {Elecsys }}(r=0.581)$, and p-tau231 $1_{\mathrm{ADx}}(r=0.724)(p<$ $0.0001)$. In $\mathrm{A} \beta$-positive MCI, $\mathrm{p}$-tau217 Lilly $_{\text {also showed the }}$ strongest correlation $(r=0.516, p<0.001)$ with A $\beta$-PET; this correlation was significantly stronger than those for p-tau181 $1_{\text {Innotest }}(r=0.312)$ and p-tau181 $1_{\text {Elecsys }}(r=0.314)$ $(p<0.001)$. Findings from voxel-wise analyses were consistent with these ROI-based results and also highlighted the stronger correlations between p-tau isoforms and A $\beta$-PET in CU individuals (eFigure 3, available from Dryad, doi.org/10. $5061 /$ dryad.4f4qrfjc7). When correlation analyses were repeated in $C U$ individuals by $A \beta$ status, significant associations between CSF p-tau measures and A $\beta$-PET were found only in the $A \beta$-positive CU group (eTable 4, available from Dryad, doi.org/10.5061/dryad.4f4qrfjc7).

Using tau-PET, CSF p-tau217 Lilly $_{\text {was }}$ most strongly associated p-tau variant in CU participants, with the strongest correlation seen in the Braak I/II ROI $(r=0.683)$. This correlation was significantly higher than those for $\mathrm{p}$-tau181 $1_{\text {Innotest }}(r=0.485)$ $(p<0.0001)$, p-tau181 Lilly $(r=0.640)(p<0.001)$, p-tau181 $1_{\text {Elecsys }}(r=0.546)(p<0.0001)$, and p-tau231 $1_{\mathrm{ADx}}(r=$ $0.605)(p<0.001)$. A similar pattern was seen when looking at Braak III/IV and V/VI.

In $\mathrm{A} \beta$-positive cognitively impaired individuals (i.e., $\mathrm{A} \beta$-positive MCI and $\mathrm{AD}$ dementia), p-tau217 $7_{\text {Lilly }}$ showed the highest correlation to tau-PET in the Braak III/IV ROI ( $r=$ $0.592)$; this association was significantly higher than for p-tau181 $1_{\text {Innotest }}(r=0.272)(p<0.0001)$, p-tau181 $1_{\text {Lilly }}(r=$ $0.486)(p<0.0001)$, p-tau181 $1_{\text {Elecsys }}(r=0.301)(p<0.001)$, and $\mathrm{p}$-tau231 $1_{\mathrm{ADx}}(r=0.393)(p<0.0001)$. This pattern also held when looking at Braak I/II and V/VI ROIs. In addition, p-tau $181_{\text {Lilly }}$ showed significantly higher correlations with tauPET across all Braak ROIs as compared to p-tau $181_{\text {Innotest }}$ p-_tau $181_{\text {Elecsys, }}$ and p-tau $231_{\mathrm{ADx}}$. Voxelwise analyses (eFigure 4) supported these findings and in particular highlighted the stronger associations of p-tau217 Lilly to tau-PET when compared to the associations between tau-PET and other p-tau variants. Similar to findings using $A \beta$-PET, associations between CSF p-tau measures and tau-PET were significant only in the $\mathrm{A} \beta$-positive $\mathrm{CU}$ group (eTable 4, available from Dryad, doi.org/10.5061/dryad.4f4qrfjc7) when repeating analyses by $\mathrm{A} \beta$ status.

\section{CSF P-Tau Slopes as a Function of $A \beta$ and Tau-PET}

Spline models examining CSF $\mathrm{p}$-tau concentrations across A $\beta$ and tau-PET are shown in Figure 2; CIs for differences in p-tau biomarkers at specified SUVR values are detailed in the Supplement (eTable 5, available from Dryad, doi.org/10. 5061/dryad.4f4qrfjc7). Using A $\beta$-PET, the slope of $\mathrm{p}$ tau217 Lilly was significantly different from those of $\mathrm{p}$ tau $181_{\text {Innotest, }}$-tau $181_{\text {Lilly, }}$ p-tau $181_{\text {Elecsys }}$, and p-tau $231_{\mathrm{ADx}}$ in $\mathrm{A} \beta$-positive $\mathrm{CU}$. The slope of $\mathrm{p}$-tau $181_{\text {Lilly }}$ differed significantly from those of $\mathrm{p}$-tau $181_{\text {Innotest }}$ and $\mathrm{p}$-tau $181_{\text {Elecsys; no }}$ significant difference was seen between CIs for $\mathrm{p}$-tau $181_{\text {Lilly }}$ and $\mathrm{p}$-tau $231_{\mathrm{ADx}}$, however. The same pattern was seen for 
Table 1 Demographic, Clinical, and Biomarker Characteristics by Diagnostic Group

\begin{tabular}{|c|c|c|c|c|c|}
\hline & $A \beta-C U(n=253)$ & $A \beta+C U(n=81)$ & $A \beta+M C l(n=84)$ & AD dementia $(n=119)$ & Non-AD $(n=92)$ \\
\hline Female & $132(52)$ & $41(51)$ & $45(54)$ & $64(54)$ & $44(48)$ \\
\hline Age, y & $60.58(14.93)$ & $71.59(8.45)$ & $71.21(8.66)$ & $77.34(7.03)$ & $69.98(9.32)$ \\
\hline Education, y & $12.68(3.22)$ & $12.05(3.71)$ & $13.28(4.92)$ & $12.39(4.48)$ & $12.57(3.62)$ \\
\hline MMSE score & $28.98(1.20)$ & $28.83(1.29)$ & $26.58(1.97)$ & $20.14(4.37)$ & $25.93(4.04)$ \\
\hline$A \beta$ positivity & $0(0)$ & $81(100)$ & $84(100)$ & $119(100)$ & $14(15)$ \\
\hline APOE $\varepsilon 4$ positivity & $94(37)$ & $56(69)$ & $64(76)$ & $85(71)$ & $28(30)$ \\
\hline CSF p-tau $181_{\text {Innotest }}, \mathrm{pg} / \mathrm{mL}$ & $39.89(13.60)$ & $62.33(21.27)$ & $68.93(25.45)$ & $88.63(35.71)$ & $39.91(15.80)$ \\
\hline CSF p-tau181 Lilly, pg/mL & $38.49(15.31)$ & $99.20(53.24)$ & $128.62(70.30)$ & $216.27(112.26)$ & $47.56(23.00)$ \\
\hline CSF p-tau181 $1_{\text {Elecsys, }}, p g / m L$ & $16.37(5.22)$ & $27.23(9.93)$ & $30.82(13.28)$ & $40.37(18.19)$ & $17.00(6.12)$ \\
\hline CSF p-tau217 Lilly, pg/mL & $48.82(25.47)$ & $206.26(146.62)$ & $316.64(218.35)$ & $616.50(358.60)$ & $67.58(52.44)$ \\
\hline CSF p-tau231 $1_{\mathrm{ADx}}, \mathrm{pg} / \mathrm{mL}$ & $9.87(4.41)$ & $23.47(10.53)$ & $28.21(13.72)$ & $40.15(16.22)$ & $10.57(4.91)$ \\
\hline$A \beta$ PET-neocortical SUVR & $0.47(0.03)$ & $0.67(0.14)$ & $0.75(0.16)$ & - & - \\
\hline Tau-PET-Braak I/II SUVR & $1.09(0.12)$ & $1.31(0.25)$ & $1.62(0.44)$ & $1.99(0.37)$ & $1.14(0.19)$ \\
\hline Tau-PET-Braak III/IV SUVR & $1.14(0.09)$ & $1.25(0.24)$ & $1.49(0.42)$ & $2.13(0.66)$ & $1.15(0.10)$ \\
\hline Tau-PET-Braak V/VI SUVR & $1.05(0.08)$ & $1.07(0.13)$ & $1.18(0.29)$ & $1.51(0.42)$ & $1.04(0.09)$ \\
\hline
\end{tabular}

Abbreviations: $A \beta=\beta$-amyloid $A D=$ Alzheimer disease; $C U=$ cognitively unimpaired; $M C I=$ mild cognitive impairment; $M M S E=$ Mini-Mental State Examination; $\mathrm{p}$-tau181 = tau phosphorylated at threonine-181; p-tau217 = tau phosphorylated at threonine-217; $\mathrm{p}$-tau231 = tau phosphorylated at threonine-231; SUVR = standardized uptake value ratio.

Values are mean (SD) or $\mathrm{n}(\%)$. Although A $\beta$ PET was only considered as a continuous value, earlier work has established an SUVR $>0.53$ as abnormal. ${ }^{14}$ Cutoffs for tau-PET SUVR were >1.48 (Braak I/II), >1.36 (Braak III/IV), and >1.35 (Braak V/VI). ${ }^{25}$

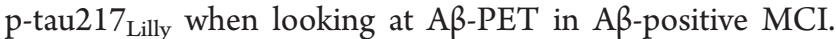
When analyses were performed separately in $\mathrm{A} \beta$-positive and $\mathrm{A} \beta$-negative $\mathrm{CU}$ individuals (eFigure 5, eTable 6, available from Dryad, doi.org/10.5061/dryad.4f4qrfjc7), increasing fold change with increasing SUVR values and separation of p-tau trajectories was largely confined to the $\mathrm{A} \beta$-positive $\mathrm{CU}$ group.

Using tau-PET SUVR in the Braak I/II ROI in CU individuals, the slope of $\mathrm{p}$-tau2 $17_{\text {Lilly }}$ differed significantly from those

Figure 1 Schematic Overview of the Included Phosphorylated Tau (P-Tau) Assays
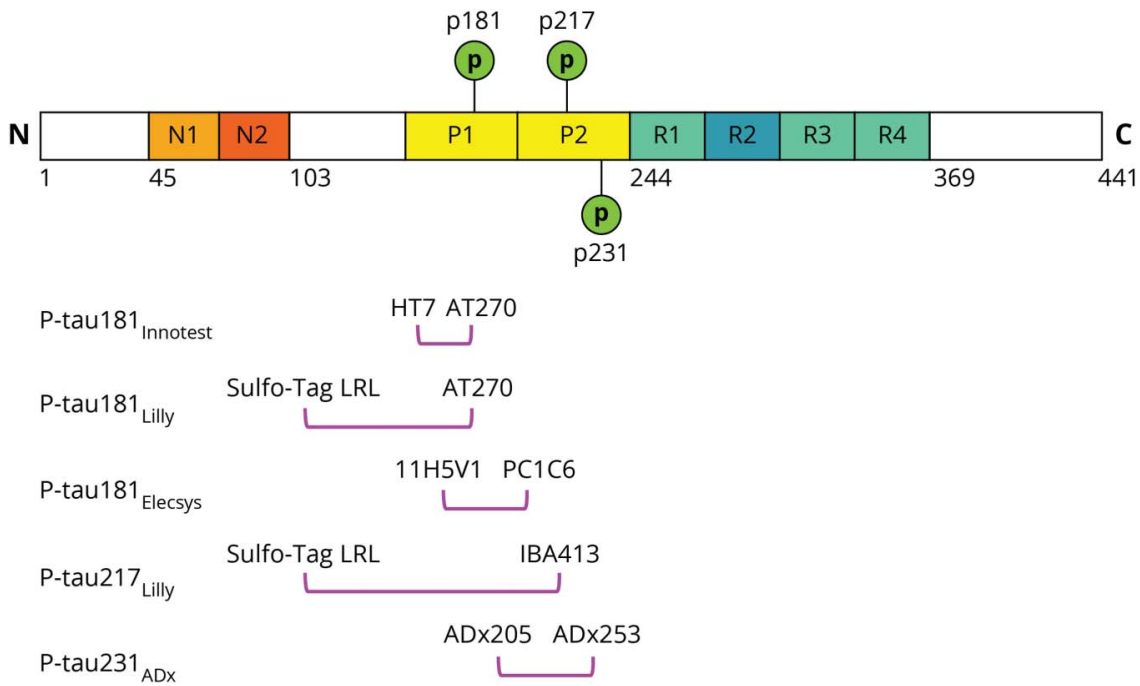

Schematic illustration of full-length tau441, including $\mathrm{N}$-terminal, proline-rich region, microtubuli binding domain, and C-terminal. Anti-tau antibodies are indicated for each of the 5 included p-tau assays under the respective epitope region. 
of p-tau $181_{\text {Innotest, }} \mathrm{p}$-tau $181_{\text {Lilly, }}$ p-tau $181_{\text {Elecsys, }}$ and $\mathrm{p}$ tau231 $1_{\mathrm{ADx}}$ at SUVR values of 1.5 or greater. The slopes of $\mathrm{p}$ tau $181_{\text {Lilly }}$ and p-tau $231_{\mathrm{ADx}}$ also differed significantly from those of p-tau $181_{\text {Innotest }}$ and p-tau $181_{\text {Elecsys; no significant }}$ difference was seen between $\mathrm{p}$-tau $181_{\mathrm{Lilly}}$ and $\mathrm{p}$-tau $231_{\mathrm{ADx}}$. The same pattern was seen when using the Braak III/IV ROI in $A \beta$-positive cognitively impaired participants and using the Braak V/VI ROI (data not shown). Similar to the analyses with $A \beta-P E T$, greater fold change at higher SUVR levels and separation of $p$-tau trajectories was largely confined to the $A \beta$ positive CU group (eFigure 5 and eTable 6, available from Dryad, doi.org/10.5061/dryad.4f4qrfjc7).

\section{CSF P-Tau Levels by Tau-PET-Based Braak Stages}

When dividing participants on the basis of their tau-PET status in Braak ROIs (Figure 3) (i.e., $\left[{ }^{18} \mathrm{~F}\right] \mathrm{RO} 948$ negative [Braak 0] or abnormal retention in the Braak I/II ROI only or abnormal retention in the Braak III/IV ROI [but not V/VI] or Braak V/VI), fold change (relative to the mean of the Braak 0 group) was highest for p-tau217 ${ }_{\text {Lilly }}$ (Braak III/IV, 4.69 [95\% CI, 4.15-5.24]; V/VI, 6.93 [95\% CI, 6.21-7.65]) followed by p-tau $181_{\text {Lilly }}$ (Braak III/IV, 2.93 [95\% CI, 2.63-3.23]; V/VI, 3.78 [95\% CI, 3.41-4.15]), p-tau231 $1_{\mathrm{ADx}}$ (Braak III/IV, 2.39 [95\% CI, 2.19-2.59]; V/VI, 2.93 [95\% CI, 2.66-3.20]), p-tau181 $1_{\text {Elecsys }}$ (Braak III/IV, 1.88 [95\% CI, 1.71-2.04]; Braak V/VI, 2.23 [95\% CI, 2.04-2.44]), and ptau181 $1_{\text {Innotest }}$ (Braak III/IV, 1.71 [95\% CI, 1.57-1.85]; Braak V/VI, 1.98 [95\% CI, 1.82-2.14]).

\section{CSF P-Tau Levels by Diagnostic Group}

By comparison to all $\mathrm{A} \beta$-negative participants, CSF $\mathrm{p}$-tau levels were increased in $\mathrm{A} \beta$-positive $\mathrm{CU}, \mathrm{MCI}$, and $\mathrm{AD}$ (Figure 4). In $\mathrm{A} \beta$-positive $\mathrm{MCI}$ and $\mathrm{AD}$, the mean fold increases (compared to $A \beta$-negative $C U$ ) were between 7.36 (95\% CI, 6.26-8.47) and 13.27 (95\% CI, 12.04-14.51) for $\mathrm{p}$ -

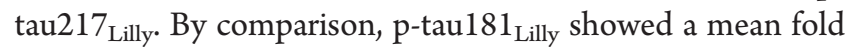
increase of between 3.38 (95\% CI, 2.98-3.79) and 5.35 (95\% CI, 4.89-5.81), while p-tau231 $1_{\mathrm{ADx}}$ showed mean fold increases of between 2.40 (95\% CI, 2.57-3.18) and 3.96 (95\% CI, 3.68-4.25). Mean fold increases were between 1.72 (95\% CI, 1.59-1.86) and 2.14 (95\% CI, 1.99-2.30) for $\mathrm{p}$ tau $181_{\text {Innotest }}$ and between 1.88 (95\% CI, 1.71-2.05) and 2.47

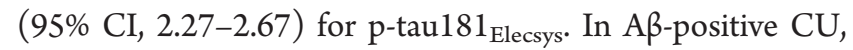
the greatest fold increase was seen for p-tau $217_{\text {Lilly }}(4.78[95 \%$ CI, 4.02-5.54), followed by p-tau $181_{\text {Lilly }}(2.61$ [95\% CI, 2.29-2.92]) and p-tau231 $1_{\mathrm{ADx}}(2.39$ [95\% CI, 2.15-2.63]), ptau $181_{\text {Elecsys }}\left(1.66\right.$ [95\% CI, 1.53-1.79]) and p-tau $181_{\text {Innotest }}$ (1.58 [95\% CI, 1.44-1.68]).

\section{Diagnostic Accuracy of CSF P-Tau Isoforms}

ROC curves and associated AUC values are shown in Figure 5. AUC values - along with sensitivity and specificity estimates at cutoffs that resulted in the highest Youden index-are reported in Table 2. The diagnostic performance of CSF p-tau for $\mathrm{AD}$ dementia vs $A \beta$-negative $C U$ (Figure $5 \mathrm{~A}$ ) and non-AD neurodegenerative disorders (Figure $5 \mathrm{~B}$ ) was highest using p-tau217 Lilly. $_{\text {For both contrasts, AUC values for p-tau217 }}$ Lilly were significantly higher than those for $\mathrm{p}$-tau $181_{\text {Innotest }}$ and p-tau $181_{\text {Elecsys }}(p<0.0001)$. For the separation of $\mathrm{AD}$ dementia from non- $\mathrm{AD}$ neurodegenerative disorders, the AUC value for $\mathrm{p}$-tau217 Lilly $_{\text {was }}$ significantly higher than that for $\mathrm{p}$-tau $181_{\text {Lilly }}$ and $\mathrm{p}$-tau $231_{\mathrm{ADx}}(p<0.05)$. For both contrasts, AUC values for $\mathrm{p}$-tau $181_{\text {Lilly }}$ were significantly higher than those for $\mathrm{p}$-tau $181_{\text {Innotest }}$ and $\mathrm{p}$-tau $181_{\text {Elecsys }}(p<0.0001)$.

When differentiating $\mathrm{A} \beta$-PET-positive from $\mathrm{A} \beta$-PET-negative participants (Figure 5C), p-tau217 $7_{\text {Lilly }}$ outperformed ptau $181_{\text {Innotest }} \mathrm{p}$-tau181 $1_{\text {Lilly, }}$ and $\mathrm{p}$-tau $181_{\text {Elecsys }}(p<0.0001)$. Using tau-PET status in the Braak III/IV (Figure 5D) and V/VI

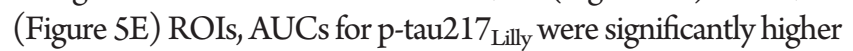
than those for $\mathrm{p}$-tau181 and $\mathrm{p}$-tau231 $1_{\mathrm{ADx}}(p<0.0001)$. Using both $\mathrm{A} \beta$ and tau-PET, the diagnostic performance of $\mathrm{p}$-tau $181_{\mathrm{Lilly}}$ was superior to that of $\mathrm{p}$-tau $181_{\text {Innotest }}$ and $\mathrm{p}$-tau $181_{\text {Elecsys }}$ $(p<0.0001)$. Using tau-PET, AUC values for $p$-tau231 $1_{\mathrm{ADx}}$ were significantly higher than those for $\mathrm{p}$-tau $181_{\text {Innotest }}$ (Braak III/IV and Braak V/VI, $p<0.0001)$, p-tau $181_{\text {Elecsys }}$ (Braak III/IV, $p<0.0001$; Braak V/VI, $p<0.01)$, and p-tau $181_{\text {Lilly }}$ (Braak III/IV and Braak V/VI, $p<0.01$ ). The AUC value of $\mathrm{p}$-tau $181_{\text {Elecsys }}$ was significantly higher than that for p-tau $181_{\text {Innotest }}$ using the Braak III/IV ROI $(p<0.05)$ but not when using the Braak V/VI ROI.

\section{Discussion}

Consistent with previous work using these assays, levels of CSF p-tau $181_{\text {Lilly }}$ and p-tau217 $7_{\text {Lilly }}$ were progressively higher across both the $\mathrm{AD}$ continuum (i.e., moving from $\mathrm{A} \beta$-positive $\mathrm{CU}$ through $\mathrm{A} \beta$-positive $\mathrm{AD}$ dementia) $)^{14,15}$ and tau-PET Braak stages. ${ }^{14}$ Furthermore, in agreement with a previous study, we found that p-tau217 Lilly had significantly higher correlations with $\mathrm{A} \beta$ and tau-PET as compared to p-tau $181_{\text {Lilly }}{ }^{14}$ and extended this finding to show that the correlation was also significantly higher than for p-tau $181_{\text {Innotest }}$ p-tau $181_{\text {Elecsys }}$, and p-tau231 2 ADx . Previously, using CSF samples taken prior to baseline tau-PET in $\mathrm{A} \beta$-positive CU, $56 \%$ of patients showed positive $\mathrm{p}$-tau217Lilly levels, compared with only $25 \%$ for p-tau $181_{\text {Lilly. }}{ }^{15}$ Combined with mass spectrometry findings in $\mathrm{AD}$ showing an increased degree of phosphorylation at threonine 217 compared with position $181,{ }^{16,34}$ these results were interpreted as suggesting that phosphorylation at position 217 may be more pronounced by comparison to other sites. Although the differences were modest, stronger correlations observed with PET would also prove consistent with findings showing that threonine 217 phosphorylation was considerably increased in $\mathrm{AD}$ as compared to threonine $181^{8,35}$ and with the preferential phosphorylation of tau at specific sites across the different stages of $\mathrm{AD} .{ }^{16,36}$ In addition, by comparison to studies using p-tau 181 measurements from commercial assays such as $\mathrm{p}$-tau $181_{\text {Innotest }}$ and p-tau $181_{\text {Elecsys, }}{ }^{37}$ larger effect sizes were seen when using p-tau $181_{\text {Lilly, }}$, p-tau217 Lilly $_{\text {, }}$ and -tau231 $1_{\mathrm{ADx}}$. 
Figure 2 CSF Phosphorylated Tau (P-Tau) Slopes as a Function of $\beta$-Amyloid (A $\beta$ ) and Tau-PET Standardized Uptake Value Ratio (SUVR)
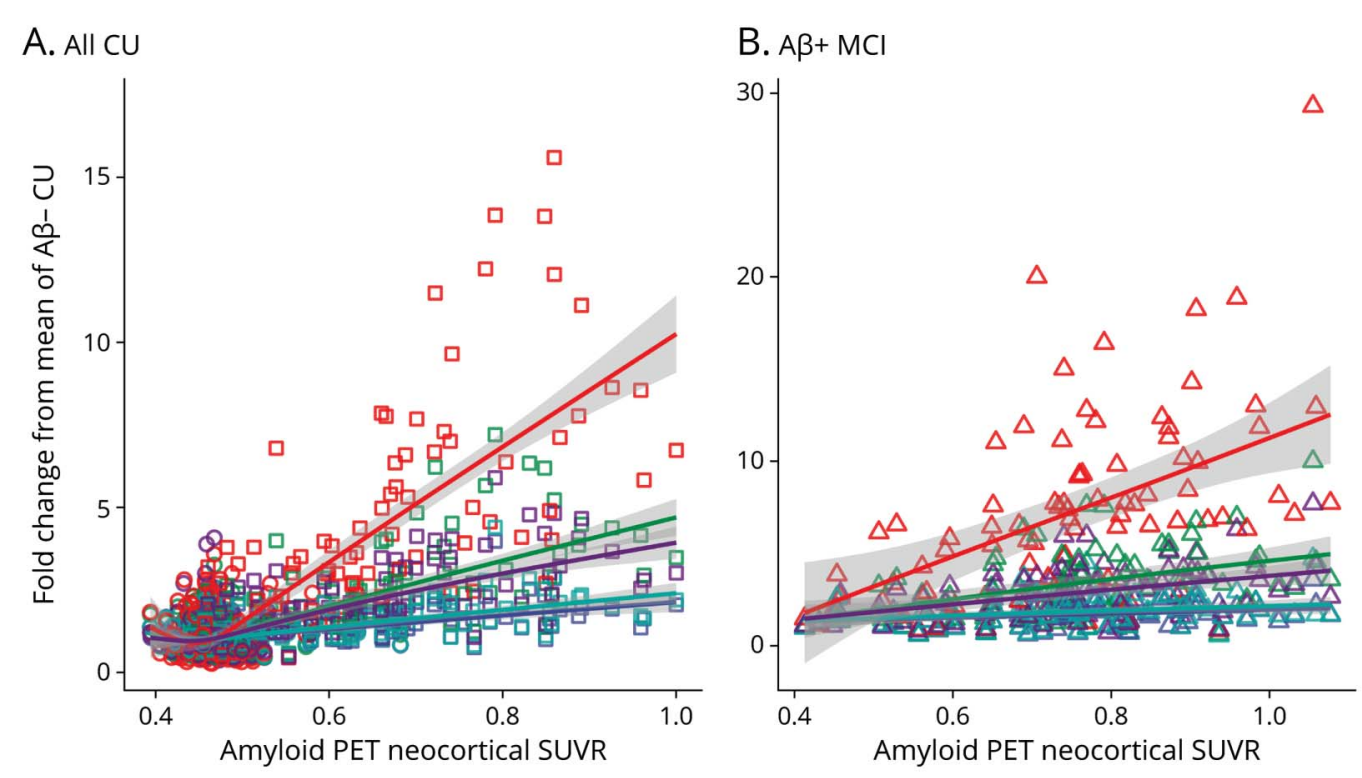

$$
\begin{aligned}
& \text { - P-tau181 } 1_{\text {Innotes }} \\
& \text { - P-tau181 } 1_{\text {Lilly }} \\
& \text { - P-tau181 } 1_{\text {Elecsys }} \\
& \text { - P-tau217 } \\
& \text { - P-tau231 }{ }_{\mathrm{ADx}} \\
& \text { - } A B-C U \\
& \text { 口 } A B+C U \\
& \triangle A \beta+M C \\
& \diamond \mathrm{AD} \text { dementia }
\end{aligned}
$$

C. All CU

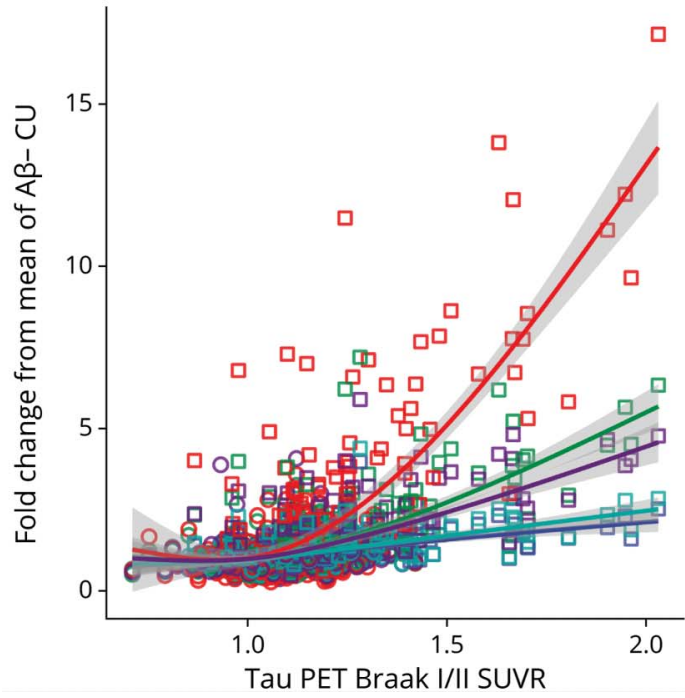

D. $A \beta+M C I$

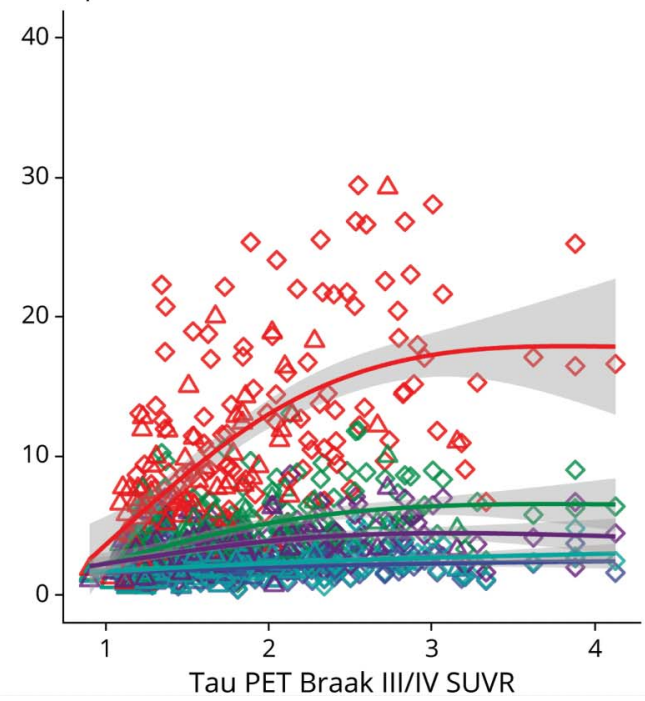

CSF p-tau levels (expressed as mean fold change relative to the mean of A $\beta$-negative cognitively unimpaired [CU] participants) are shown against global $A \beta$ PET neocortical SUVR across all CU participants $(A)$ and in $A \beta$-positive mild cognitive impairment (MCI) (B). Panels $C$ and D show corresponding plots for tauPET in all CU participants (Braak I/II) and in all AB-positive cognitively impaired participants (Braak III/IV) (i.e., A $A$-positive MCI and Alzheimer disease [AD] dementia combined). Generalized additive models with cubic regression splines were used to compare the slopes of CSF $p$-tau isoforms across different $A \beta$ and tau-PET SUVR values. Shaded gray areas indicate $95 \%$ confidence intervals.

Using spline-based analyses, we compared the slopes of p-tau isoforms in relation to continuous $A \beta$ and tau-PET SUVR values. These analyses were performed in $\mathrm{CU}$ individuals and in cognitively impaired $\mathrm{A} \beta$-positive patients. Although greater PET SUVR values were associated with higher CSF p-tau concentrations for all isoforms, no significant differences were seen in the courses of $\mathrm{p}$-tau $181_{\mathrm{Lilly}}$ and $\mathrm{p}$-tau2 $231_{\mathrm{ADx}}$. By contrast, comparison of CIs showed that the slope of $\mathrm{p}$ tau217 $7_{\text {Lilly }}$ diverged from those of $\mathrm{p}$-tau $181_{\text {Lilly }}$ and $\mathrm{p}$ tau231 $1_{\mathrm{ADx}}$ across a range of SUVR values, particularly in the CU group when using tau-PET in the Braak I/II ROI. These findings are consistent with increases in the active production of soluble tau in the presence of aggregated $A \beta^{8}$ and, possibly, with the idea that the relative phosphorylation of tau at specific sites varies across the course of $\mathrm{AD} .{ }^{16,36}$ Although findings with tau-PET in the cognitively impaired group suggest a plateau in the course of all 3 isoforms-possibly due to a process though which phosphorylation rates are reduced due to sequestration by hyperphosphorylated aggregates ${ }^{38,39}$ - phosphorylation of threonine 217 may continue to increase later into the disease course, similar, for example, to what has been reported for $\mathrm{p}$ tau205. ${ }^{16}$ This, combined with p-tau217 $7_{\text {Lilly }}$ possibly showing a higher specificity for $\mathrm{AD},{ }^{14}$ may explain the higher AUC values seen for p-tau217 Lilly. Although a tau-centric hypothesis 


\section{A. CSF P-tau181 ${ }_{\text {Innotest }}$}

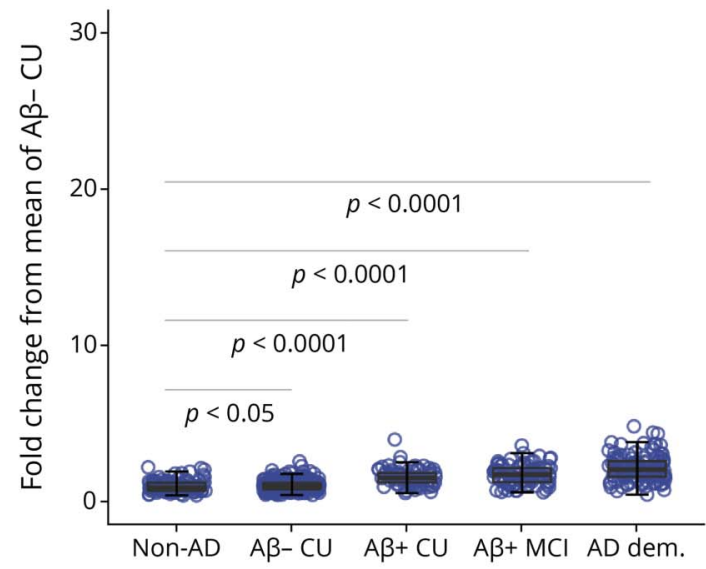

C. CSF P-tau181 $1_{\text {Elecsys }}$

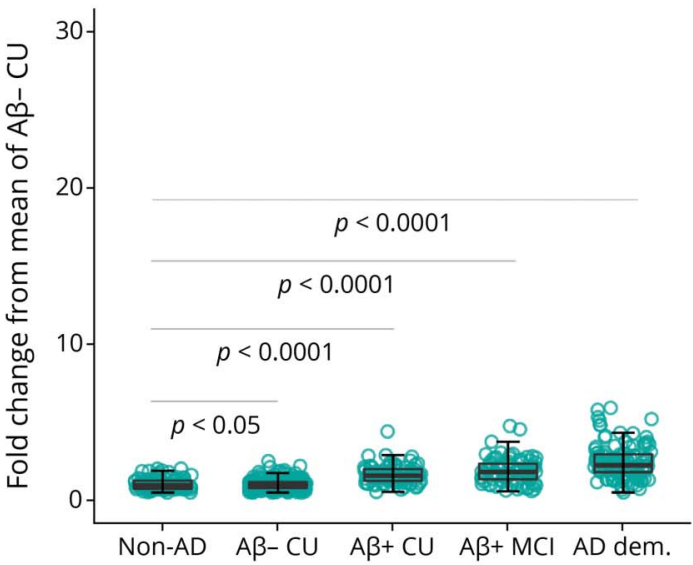

E. CSF P-tau231 ${ }_{A D X}$

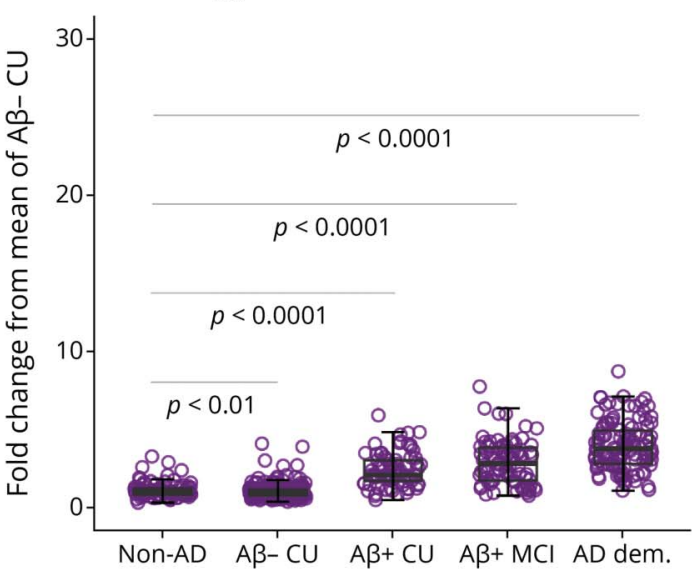

B. CSF P-tau181 Lilly

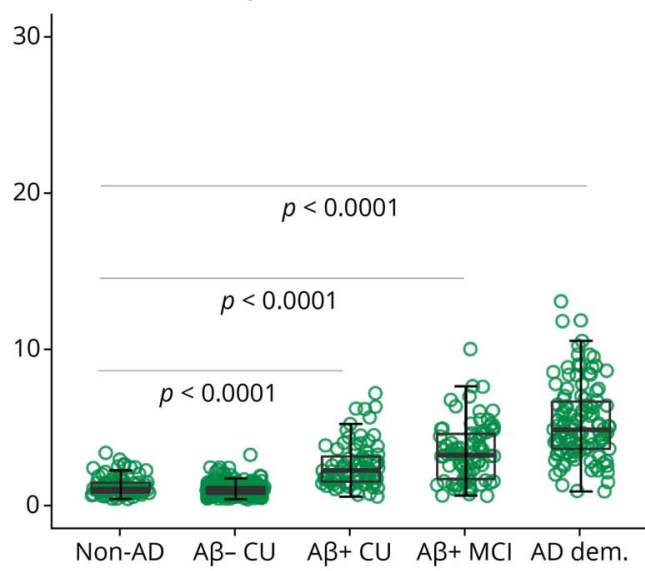

D. CSF P-tau217

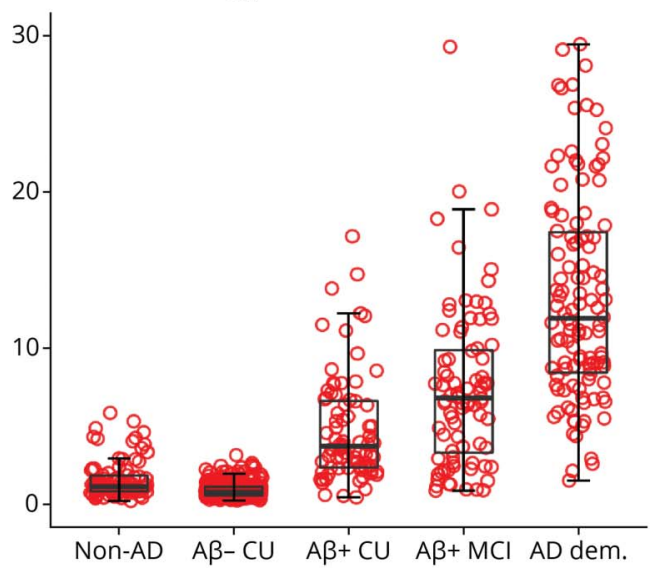

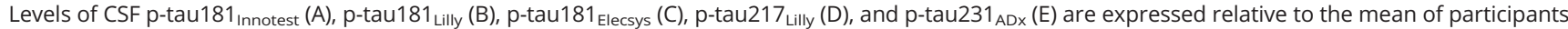
showing no abnormal tau-PET standardized uptake value ratio (SUVR) values in any of the investigated regions of interest (Braak $0, n=437$ ). Tau positivity in Braak stages III/VI was established using a priori cutoffs based on the mean SUVR within a given region of interest plus 2.5 SD among $\beta$-amyloid (A $\beta$ )-negative young controls. Solid gray horizontal lines indicate age-adjusted group comparisons: Alzheimer disease (AD) dementia higher than all groups ( $p<0.001)$; $A \beta-$ positive mild cognitive impairment (MCI) higher than cognitively unimpaired (CU) and non-AD $(p<0.001)$; $A \beta$-positive CU higher than $A \beta-$-negative $C U$ and non$\mathrm{AD}(p<0.001)$. In order to facilitate comparison between $p$-tau measures, $\mathrm{y}$-axes were scaled to the maximum fold change seen across biomarkers. $\mathrm{AD}$ dem. $=$ Alzheimer disease dementia; non-AD = non-Alzheimer disease neurodegenerative disorders.

ascribing a primary role to tau ${ }^{40}$ has been proposed as an alternative to the view that $\mathrm{AD}$ is caused by the accumulation of $\mathrm{A} \beta$ in the brain, ${ }^{41}$ both spline- and correlation-based sensitivity analyses in $\mathrm{CU}$ individuals by $\mathrm{A} \beta$ status showed there to be little association with $A \beta$ and tau-PET in $A \beta$-negative $C U$ individuals. 
A. CSF P-tau181 $1_{\text {Innotest }}$

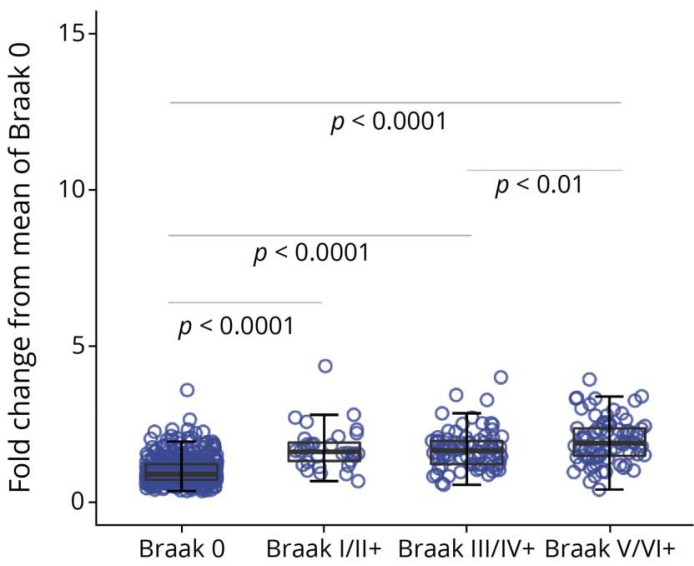

C. CSF P-tau181 $1_{\text {Elecsys }}$

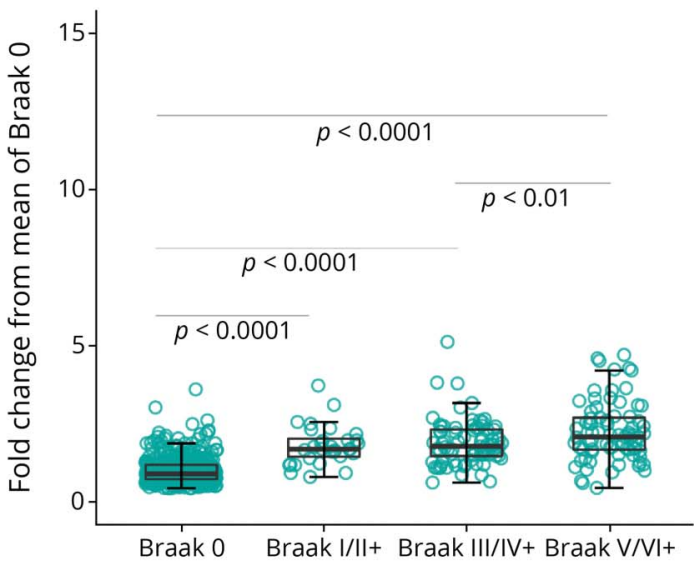

E. CSF P-tau231 ${ }_{A D X}$

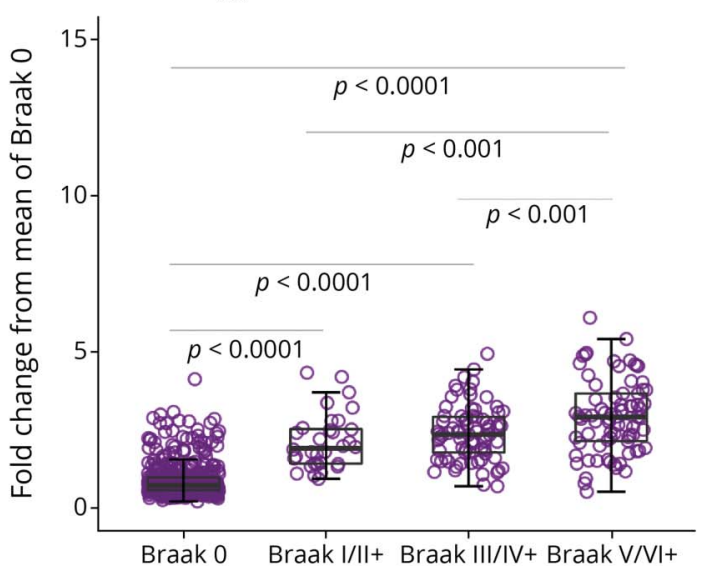

B. CSF P-tau181 $1_{\text {Lilly }}$

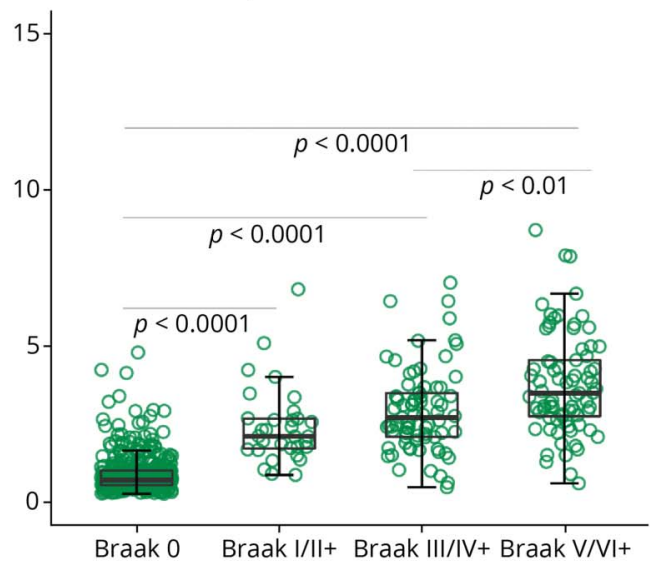

D. CSF P-tau217 $7_{\text {Lilly }}$

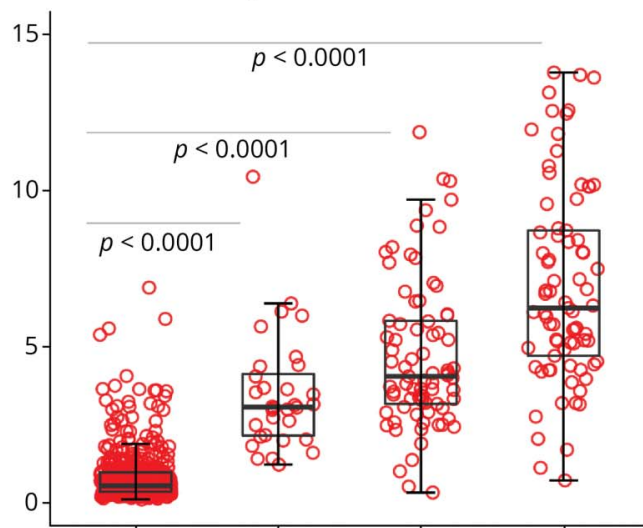

Braak 0 Braak I/II+ Braak III/IV+ Braak V/VI+

Levels of CSF p-tau181 $1_{\text {Innotest }}(A)$, p-tau181 $(A \beta)$-negative participants $(n=253)$. Solid gray horizontal lines indicate age-adjusted group comparisons: Alzheimer disease (AD) dementia higher than all groups $(p<0.001)$; A $\beta$-positive mild cognitive impairment higher than cognitively unimpaired $(C U)$ and non-AD neurodegenerative disorders $(p<0.001)$; $A \beta$ positive $C U$ higher than $A \beta$-negative $C U$ and non-AD $(p<0.001)$. In order to facilitate comparison between $p$-tau measures, $y$-axes were scaled to the maximum fold change seen across biomarkers. In order to facilitate comparison between p-tau measures, y-axes were scaled to the maximum fold change seen across biomarkers.

A recent study focused on characterizing the patterns of change in p-tau2 $231_{\mathrm{ADx}}$ and $\mathrm{p}$-tau $181_{\text {Elecsys }}$ in preclinical $\mathrm{AD}{ }^{42}$ In ROC analyses, the authors found that $\mathrm{p}$-tau $231_{\mathrm{ADx}}$ had statistically significant higher predictive accuracies than $\mathrm{p}$ tau181 $1_{\text {Elecsys }}$ for discriminating $A \beta$-positive from $A \beta$-negative $\mathrm{CU}$ individuals. Moreover, $\mathrm{p}$-tau $231_{\mathrm{ADx}}$ showed an AUC that 

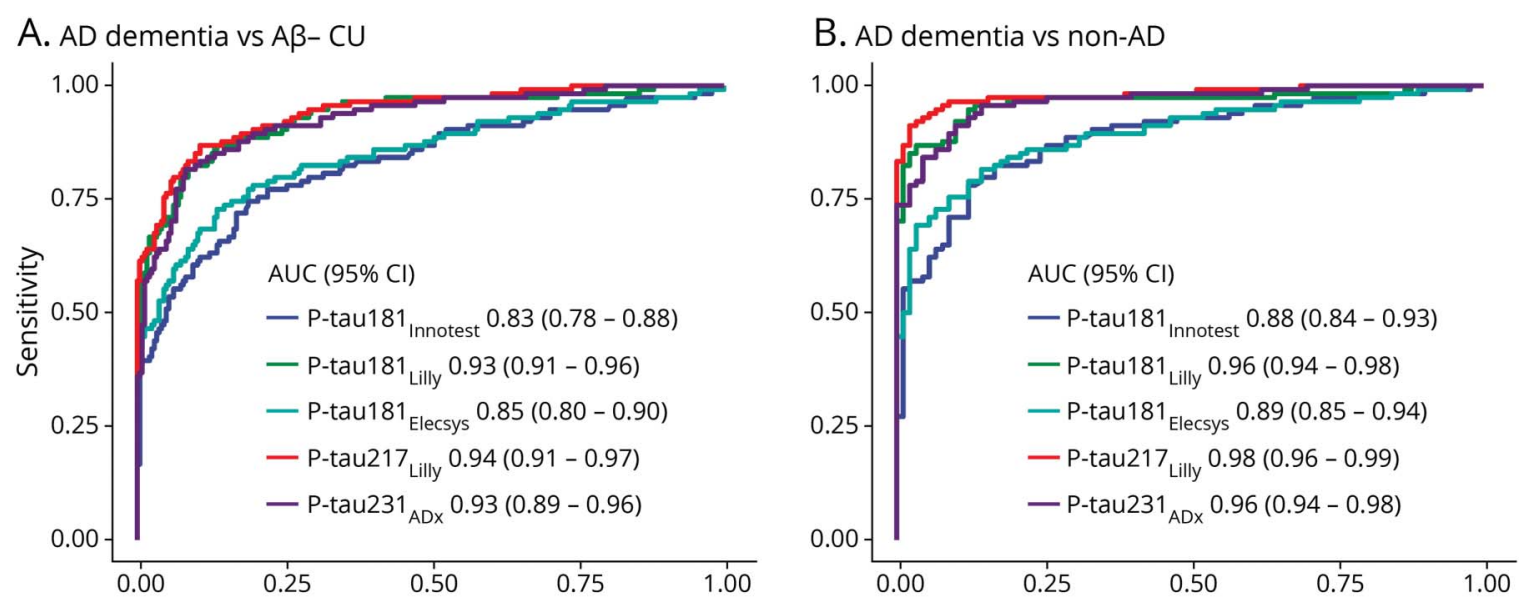

C. A PET+ (Neocortical ROI)

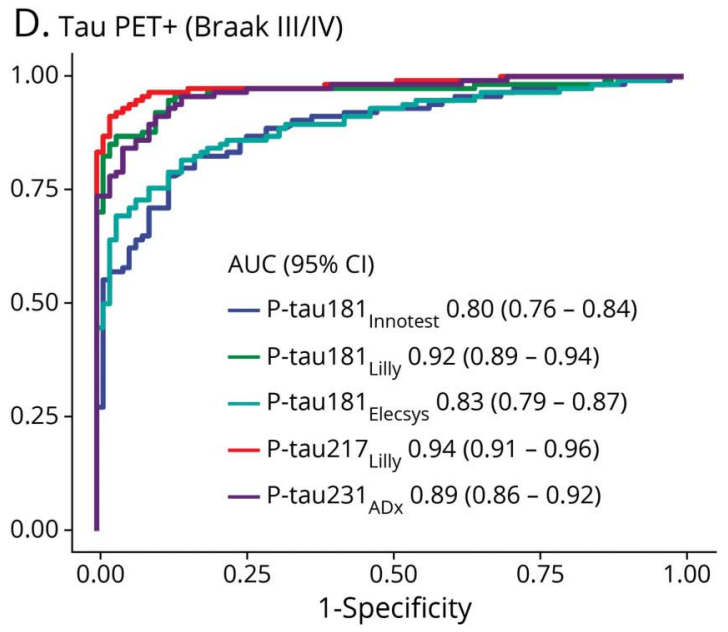

E. Tau PET+ (Braak V/VI)

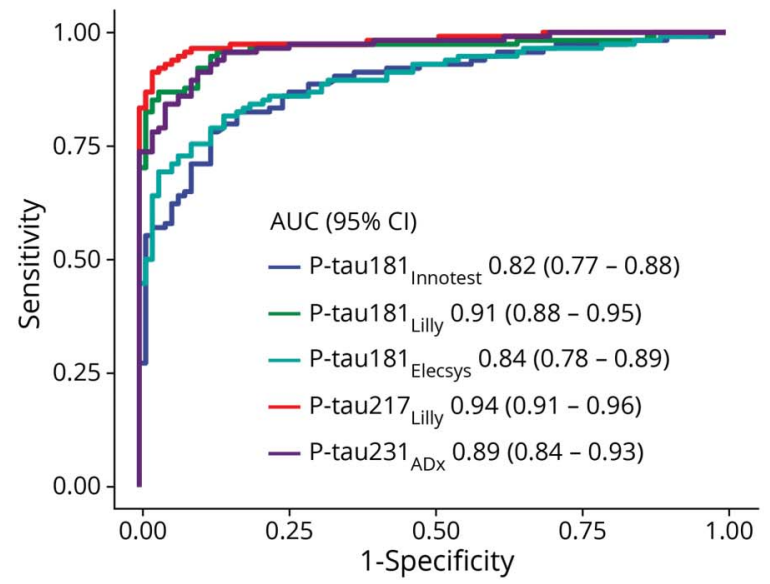

Receiver operating characteristic curves are shown for the following groups: Alzheimer disease (AD) dementia vs $\beta$-amyloid (A 3 )-negative cognitively unimpaired (CU) (A), AD dementia vs non-AD disorders (B), AB-PET positive vs negative (C), and tau-PET positive vs negative using the Braak III/IV (D) and V/VI (E) regions of interest (ROIs). $A \cup C=$ area under the receiver operating characteristic curve; $\mathrm{Cl}=$ confidence interval.

was higher than that of p-tau $181_{\text {Elecsys. Although our findings }}$ showing that $\mathrm{p}$-tau231 $1_{\mathrm{ADx}}$ had higher AUCs compared to $\mathrm{p}$ tau $181_{\text {Elecsys }}$ and p-tau $181_{\text {Innotest }}$ are consistent with this, our results also suggest that $\mathrm{p}$-tau $231_{\mathrm{ADx}}$ is similar to $\mathrm{p}$-tau $181_{\text {Lilly. }}$. In a related study by Karikari et al., ${ }^{43} \mathrm{~N}$-p-tau 217 showed higher diagnostic performance for identifying $A \beta$ pathology and $\mathrm{AD}$ at the MCI stage compared to established p-tau181 assays ( $\mathrm{p}$-tau $181_{\text {Innotest }}$ and $\mathrm{p}$-tau $\left.181_{\text {Lumipulse }}\right)$, but not compared to N-p-tau181. Possibly complicating this comparison, however, is the comparatively small number of prodromal $\mathrm{AD}$ cases. Although our results cannot be directly compared because of differences in the assays used for p-tau217, studies 
Table 2 Area Under the Receiver Operating Characteristic Curve (AUC) Values and Sensitivity/Specificity at Youden Index-Based Cutoffs

\begin{tabular}{|c|c|c|c|c|c|}
\hline & \multirow[b]{2}{*}{ Cutoff } & \multicolumn{3}{|c|}{ Performance $(95 \% \mathrm{Cl})$} & \multirow[b]{2}{*}{$p$ Values } \\
\hline & & AUC & Sensitivity & Specificity & \\
\hline \multicolumn{6}{|l|}{$A D$ dementia vs $A \beta-C U$} \\
\hline CSF p-tau181 Innotest $^{a}$ & 57.73 & $0.83(0.78-0.88)$ & $75.44(59.65-84.21)$ & $81.89(74.90-93.83)$ & \multirow{5}{*}{ 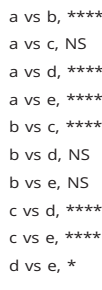 } \\
\hline CSF p-tau181 Lillyy $^{b}$ & 86.59 & $0.93(0.91-0.96)$ & 85.09 (77.19-92.98) & $89.30(82.30-94.65)$ & \\
\hline CSF p-tau181 Elecsys $^{c}$ & 25.28 & $0.85(0.80-0.90)$ & $75.44(64.04-85.09)$ & $85.60(76.13-93.00)$ & \\
\hline CSF p-tau217 Lilly $^{d}$ & 194.32 & $0.94(0.91-0.97)$ & $86.84(78.07-92.98)$ & $90.53(84.36-95.88)$ & \\
\hline CSF p-tau231 $1_{A D x}{ }^{e}$ & 20.14 & $0.93(0.89-0.96)$ & $84.21(76.32-92.11)$ & $90.53(81.07-95.06)$ & \\
\hline \multicolumn{6}{|l|}{$A D$ dementia vs non-AD } \\
\hline CSF p-tau $181_{\text {Innotest }^{a}}$ & 55.75 & $0.88(0.84-0.93)$ & $81.58(71.05-90.35)$ & $86.67(76.67-94.44)$ & \multirow{5}{*}{ 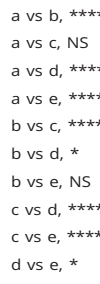 } \\
\hline CSF p-tau181 Lilly ${ }^{b}$ & 99.87 & $0.96(0.94-0.98)$ & $91.23(81.58-98.25)$ & $95.56(85.56-100)$ & \\
\hline CSF p-tau181 Elecsys $^{c}$ & 25.44 & $0.89(0.85-0.94)$ & $79.82(65.79-89.47)$ & $91.11(80.00-98.89)$ & \\
\hline CSF p-tau217 Lilly $^{d}$ & 190.87 & $0.98(0.96-0.99)$ & $93.86(87.72-98.25)$ & $96.67(91.11-100)$ & \\
\hline CSF p-tau $231_{A D x}{ }^{e}$ & 18.76 & $0.96(0.94-0.98)$ & $92.98(82.46-98.25)$ & $91.11(82.22-98.89)$ & \\
\hline \multicolumn{6}{|c|}{$A \beta$ PET+ vs A $\beta$ PET- (neocortical ROI) } \\
\hline CSF p-tau $181_{\text {Innotest }}{ }^{a}$ & 53.87 & $0.74(0.69-0.80)$ & $66.23(51.66-76.16)$ & 76.98 (67.17-89.06) & \multirow{5}{*}{ 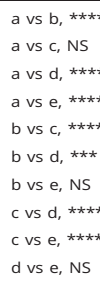 } \\
\hline CSF p-tau181 Lillyy $^{b}$ & 71.49 & $0.83(0.79-0.88)$ & $73.51(64.90-80.79)$ & $87.92(81.51-93.58)$ & \\
\hline CSF p-tau181 Elecsys $^{c}$ & 23.64 & $0.77(0.72-0.82)$ & $66.23(55.63-76.82)$ & $83.02(72.45-89.82)$ & \\
\hline CSF p-tau217 Lilly $^{d}$ & 137.55 & $0.86(0.82-0.90)$ & 72.85 (63.58-80.79) & $90.57(83.40-96.60)$ & \\
\hline CSF p-tau $231_{A D x}{ }^{e}$ & 16.45 & $0.85(0.80-0.89)$ & $76.82(67.55-84.11)$ & $0.8528(78.49-91.70)$ & \\
\hline \multicolumn{6}{|c|}{ Tau-PET+ vs tau-PET- (Braak III/IV ROI) } \\
\hline CSF p-tau181 Innotest $^{a}$ & 59.37 & $0.80(0.76-0.84)$ & $72.73(57.14-81.82)$ & $75.27(69.37-87.96)$ & \multirow{5}{*}{ 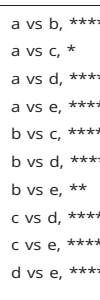 } \\
\hline CSF p-tau181 Lilly $^{b}$ & 99.82 & $0.92(0.89-0.94)$ & $84.42(75.32-92.21$ & $87.31(78.34-94.31)$ & \\
\hline CSF p-tau181 ${ }_{\text {Elecsys }}^{c}$ & 24.25 & $0.83(0.79-0.87)$ & $76.62(62.32-85.06)$ & $75.71(69.15-89.06)$ & \\
\hline CSF p-tau217 Lilly $^{d}$ & 235.21 & $0.94(0.91-0.96)$ & $87.01(81.82-92.86)$ & $90.37(85.78-93.00)$ & \\
\hline CSF p-tau231 $1_{A D x}{ }^{e}$ & 17.10 & $0.89(0.86-0.92)$ & $88.96(74.03-95.45)$ & $75.93(69.58-90.37)$ & \\
\hline \multicolumn{6}{|c|}{ Tau-PET+ vs tau-PET- (Braak V/VI ROI) } \\
\hline CSF p-tau $181_{\text {Innotest }}{ }^{a}$ & 69.41 & $0.82(0.77-0.88)$ & $74.03(62.34-87.01)$ & $82.02(67.60-88.76)$ & \multirow{5}{*}{ 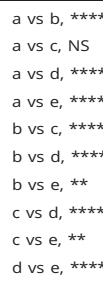 } \\
\hline CSF p-tau181 Lilly ${ }^{b}$ & 127.22 & $0.91(0.88-0.95)$ & $88.31(80.52-96.10)$ & $86.79(78.65-91.20)$ & \\
\hline CSF p-tau181 ${ }_{\text {Elecsys }}^{c}$ & 29.19 & $0.84(0.78-0.89)$ & $77.92(63.64-88.31)$ & $80.52(67.98-91.01)$ & \\
\hline CSF p-tau217 $_{\text {Lilly }^{d}}{ }^{d}$ & 326.04 & $0.94(0.91-0.96)$ & $90.91(83.12-97.40)$ & $90.26(85.02-93.63)$ & \\
\hline CSF p-tau231 $1_{A D x}{ }^{e}$ & 26.95 & $0.89(0.84-0.93)$ & $85.71(74.03-97.40)$ & $81.84(64.42-89.51)$ & \\
\hline
\end{tabular}

Abbreviations: $A \beta=\beta$-amyloid; $A D=$ Alzheimer disease; $C I=$ confidence interval; $C U$ = cognitively unimpaired; $N S=$ not statistically significant; $p$-tau $181=$ tau phosphorylated at threonine-181; p-tau217 = tau phosphorylated at threonine-217; $\mathrm{p}$-tau231 = tau phosphorylated at threonine-231; ROI = region of interest. $p$ Values (Bonferroni corrected) are for the comparison of AUC values across $p$-tau measures. Superscripted letters $\left({ }^{\text {a-e }}\right)$ indicate the different $p$-tau measures. ${ }^{\star} p<0.05$.

$* \star p<0.01$.

$* * \star p<0.001$

$* * * \star p<<0.0001$

thus far suggest, overall, that p-tau217 assays are generally more sensitive. Further studies directly comparing these assays are required, however, as well as whether p-tau $231_{\mathrm{ADx}}$ and p-tau $181_{\text {Lilly }}$ begin to increase at the same time point or if p-tau $231_{\mathrm{ADx}}$ starts to increase earlier in order to help establish the temporal dynamics of these different measures. Here, 
longitudinal studies comparing p-tau181, p-tau217, and p-tau231 will prove crucial.

Clinical utility in terms of fold change with respect to levels in $\mathrm{A} \beta$-negative $\mathrm{CU}$ individuals varied across the investigated CSF p-tau measures. Although sharing the same p-tau181specific antibody (AT270), the Innotest and Lilly p-tau181 assays had different total tau (i.e., not binding to the phosphorylation site) antibodies and showed large differences in fold change. This indicates the importance of tau isoforms or fragmentation with respect to clinical utility: should fragmentation occur in the region of the protein where the 2 totaltau antibodies bind, this could lead to the measurement of different pools of tau present in CSF. This hypothesis is reinforced by the fact that $\mathrm{p}$-tau $181_{\text {Innotest }}$ and $\mathrm{p}$-tau $181_{\text {Elecsys }}$ assays showed similar performance despite differing in both $\mathrm{p}$ tau181-specific and total tau antibodies; presumably, this reflects these assays measuring the same tau isoform/fragment. The influence of the total tau antibody on the clinical utility of p-tau 181 is thus significant, as p-tau $181_{\text {Lilly }}$ showed about double the fold change as $\mathrm{p}$-tau181 1 Innotest and $\mathrm{p}$-tau181 1 Elecsys in $\mathrm{AD}$. One explanation for the differences in fold change is also the possibility of a different binding affinity of the total tau antibody for tau, which could lead to differences in the measured signal with increasing protein concentrations. However, the Lilly assays showed that $\mathrm{p}$-tau217 showed greater fold change compared to p-tau181 when using the same total tau antibody in combination with different phosphorylation-specific antibodies. The variability observed in the fold change of the measurements with p-tau181 assay cannot therefore be fully explained by technical differences of the assay or antibody affinity. One could speculate that the binding of antibodies to different phospho-epitopes could lead to conformational changes in the protein and therefore different affinity of the total tau antibody, but further studies are needed to demonstrate this. Similarly, we do not yet know whether p-tau231 will be better or worse in a head-to-head comparison to $\mathrm{p}$-tau 217 as the $\mathrm{p}$-tau2 $231_{\mathrm{ADx}}$ assay uses a different total tau antibody.

Recent mass spectrometry-based work $^{44}$ addressing tau PTMs has shown that p-tau181, p-tau217, and p-tau231 appear to be indicators of early $\mathrm{AD}$ pathology based on Braak NFT staging of postmortem brain tissue. ${ }^{18}$ In a related study exploring the biochemical link between measures of $A \beta$ and tau phosphorylation, however, a somewhat different conclusion was reached: while soluble p-tau181, p-tau217, and p-tau231 were highly correlated to $A \beta$ levels, ${ }^{45}$ the highest degree of tau phosphorylation was observed in the insoluble fractions of $\mathrm{AD}$ brain tissue, suggesting that correlations with $\mathrm{A} \beta$ and tau aggregates may be more complex than simple linear relations. Despite this recent progress in understanding the link between abnormal PTMs and the aggregation of tau in $\mathrm{AD}$, additional studies are required to understand how such abnormal PTMs are reflected in predominantly C-terminally truncated tau. ${ }^{8,46}$ Current findings nevertheless highlight the importance of mapping PTMs in order to better understand the pathophysiology of $\mathrm{AD}$; moreover, increased insight into the role of PTMs will facilitate the identification of novel therapeutic targets and improve $\mathrm{AD}$ diagnostics.

Strengths of our study include the large number of patients spanning the $\mathrm{AD}$ continuum, within-subject measurements of multiple CSF p-tau isoforms and their comparison to the widely used p-tau181 from Innotest and Elecsys, and the availability of $A \beta$ and tau-PET imaging. Moreover, the use of mid-fragments across all p-tau measures allowed for a more direct comparison of p-tau biomarkers. This study has limitations, however. First, our inferences as to the ordering of changes in p-tau isoforms over the course of $\mathrm{AD}$ are based on cross-sectional data whereas longitudinal studies are needed to accurately address this question. Second, we did not have A $\beta$ $\mathrm{PET}$ in the $\mathrm{AD}$ dementia group. Although earlier work indicated that $\mathrm{A} \beta$ pathology may reach a plateau during the dementia phase of $\mathrm{AD},{ }^{47}$ recent findings suggest that this may not be the case. $^{48}$ As such, we were not able to examine the effect of higher A $\beta$-PET SUVR values on $p$-tau isoforms but were nonetheless able to identify the significantly higher dynamic range of $\mathrm{p}$ tau217 Lilly using the available A $\beta$-PET from participants with out dementia. Although we acknowledge the lack of A $\beta$-PET across all groups as a limitation, very high concordance is seen between CSF $A \beta 42 / A \beta 40$ and A $\beta$-PET. ${ }^{49}$ As such, the 2 measures provide similar information with respect to defining $\mathrm{A} \beta$ status. As we were interested in the relationship between p-tau and the amount of fibrillary brain $A \beta$, however, we chose $\mathrm{A} \beta$-PET as this measure reflects the cumulative burden of accumulated $A \beta$ pathology while CSF $A \beta 42 / 40$ reflects the production and clearance of $A \beta 42$ and $A \beta 40$ at a given time point. ${ }^{50}$ Lastly, though our study used the same assay for $\mathrm{p}$-tau231 $\mathrm{ADx}$ and p-tau $181_{\text {Elecsys }}$ as used in the study by Suárez-Calvet et al., ${ }^{42}$ assays for p-tau181 and p-tau217 differed. In order to more definitively address the ordering of $\mathrm{p}$-tau biomarkers, future work comparing phosphorylation epitopes will require the use of assays that are as similar as possible using head-to-head designs and validation in independent datasets.

We found that CSF p-tau217 $7_{\text {Lilly }}$ more strongly correlated with $\mathrm{A} \beta$ and tau-PET and showed greater increases as compared to $\mathrm{p}$-tau $181_{\text {Innotest }}$, $\mathrm{p}$-tau $181_{\text {Lilly, }}$ p-tau $181_{\text {Elecsys }}$, and $\mathrm{p}$ tau231 $1_{\mathrm{ADx}}$ in $\mathrm{AD}$ dementia and across tau-PET Braak stages. Moreover, CSF p-tau217 Lilly $_{\text {showed greater discriminative }}$ accuracy for $\mathrm{AD}$ dementia, as compared to CSF p-tau $181_{\text {In- }}$ notest, $\mathrm{p}$-tau $181_{\text {Lilly, }}$-tau $181_{\text {Elecsys, }}$ and p-tau231 $1_{\mathrm{ADx}}$. These results suggest that CSF p-tau217 Lilly $_{\text {should be the preferred }}$ $\mathrm{p}$-tau variant to use for $\mathrm{AD}$ diagnostics and for tracking disease progression (e.g., as an outcome in clinical $\mathrm{AD}$ trials).

\section{Study Funding}

The study was supported by the Swedish Research Council (2016-00906), the Knut and Alice Wallenberg Foundation (2017-0383), the Marianne and Marcus Wallenberg Foundation (2015.0125), the Strategic Research Area MultiPark (Multidisciplinary Research in Parkinson's disease) at Lund University, the Swedish Alzheimer Foundation (AF-745911), the Swedish Brain Foundation (FO2019-0326), The 
Parkinson Foundation of Sweden (1280/20), the Skåne University Hospital Foundation (2020-O000028), Regionalt Forskningsstöd (2020-0314), and the Swedish federal government under the ALF agreement (2018-Projekt0279). The funding sources had no role in the design and conduct of the study; in the collection, analysis, and interpretation of the data; or in the preparation, review, or approval of the manuscript. The precursor of $\left[{ }^{18} \mathrm{~F}\right]$ flutemetamol was sponsored by GE Healthcare. The precursor of $\left[{ }^{18} \mathrm{~F}\right] \mathrm{RO} 948$ was provided by Roche.

\section{Disclosure}

A. Leuzy, S. Janelidze, N. Mattsson-Carlgren, S. Palmqist, C. Cicognola, and E. Stomrud report no conflicts of interest. D. Jacobs is a current employee and E. Vanmechelen is cofounder of $\mathrm{ADx}$ NeuroSciences. J.L. Dage is a current employee of Eli Lilly and Company. O. Hansson has acquired research support (for the institution) from AVID Radiopharmaceuticals, Biogen, Eli Lilly, Eisai, GE Healthcare, Pfizer, and Roche. In the past 2 years, he has received consultancy/speaker fees from AC Immune, Alzpath, Biogen, Cerveau, and Roche. Go to Neurology.org/N for full disclosures.

\section{Publication History}

Received by Neurology January 16, 2021. Accepted in final form August 19, 2021.

Appendix Authors

\begin{tabular}{|c|c|c|}
\hline Name & Location & Contribution \\
\hline $\begin{array}{l}\text { Antoine Leuzy, } \\
\text { PhD }\end{array}$ & $\begin{array}{l}\text { Lund University, Malmö, } \\
\text { Sweden }\end{array}$ & $\begin{array}{l}\text { Designed and conceptualized } \\
\text { study; analyzed the data; } \\
\text { drafted the manuscript for } \\
\text { intellectual content }\end{array}$ \\
\hline $\begin{array}{l}\text { Shorena } \\
\text { Janelidze, PhD }\end{array}$ & $\begin{array}{l}\text { Lund University, Malmö, } \\
\text { Sweden }\end{array}$ & $\begin{array}{l}\text { Designed and conceptualized } \\
\text { study; revised the manuscript } \\
\text { for intellectual content }\end{array}$ \\
\hline $\begin{array}{l}\text { Niklas } \\
\text { Mattsson- } \\
\text { Carlgren, MD, } \\
\text { PhD }\end{array}$ & $\begin{array}{l}\text { Lund University, Malmö, } \\
\text { Sweden }\end{array}$ & $\begin{array}{l}\text { Designed and conceptualized } \\
\text { study; revised the manuscript } \\
\text { for intellectual content }\end{array}$ \\
\hline $\begin{array}{l}\text { Sebastian } \\
\text { Palmqvist, } \\
\text { MD, PhD }\end{array}$ & $\begin{array}{l}\text { Lund University, Malmö; } \\
\text { Skåne University Hospital, } \\
\text { Lund, Sweden }\end{array}$ & $\begin{array}{l}\text { Designed and conceptualized } \\
\text { study; revised the manuscript } \\
\text { for intellectual content }\end{array}$ \\
\hline $\begin{array}{l}\text { Dirk Jacobs, } \\
\text { PhD }\end{array}$ & $\begin{array}{l}\text { ADx NeuroSciences NV, } \\
\text { Ghent, Belgium }\end{array}$ & $\begin{array}{l}\text { Major role in the acquisition } \\
\text { of data; interpreted the data; } \\
\text { revised the manuscript for } \\
\text { intellectual content }\end{array}$ \\
\hline $\begin{array}{l}\text { Claudia } \\
\text { Cicognola, MD, } \\
\text { PhD }\end{array}$ & $\begin{array}{l}\text { Lund University, Malmö; } \\
\text { Skåne University Hospital, } \\
\text { Lund, Sweden }\end{array}$ & $\begin{array}{l}\text { Interpreted the data; revised } \\
\text { the manuscript for } \\
\text { intellectual content }\end{array}$ \\
\hline $\begin{array}{l}\text { Erik Stomrud, } \\
\text { MD, PhD }\end{array}$ & $\begin{array}{l}\text { Lund University, Malmö; } \\
\text { Skåne University Hospital, } \\
\text { Lund, Sweden }\end{array}$ & $\begin{array}{l}\text { Major role in the acquisition } \\
\text { of data; revised the } \\
\text { manuscript for intellectual } \\
\text { content }\end{array}$ \\
\hline $\begin{array}{l}\text { Eugeen } \\
\text { Vanmechelen, } \\
\text { PhD }\end{array}$ & $\begin{array}{l}\text { ADx NeuroSciences NV, } \\
\text { Ghent, Belgium }\end{array}$ & $\begin{array}{l}\text { Major role in the acquisition } \\
\text { of data; interpreted the data; } \\
\text { revised the manuscript for } \\
\text { intellectual content }\end{array}$ \\
\hline
\end{tabular}

Appendix (continued)

\begin{tabular}{lll}
\hline Name & Location & Contribution \\
\hline $\begin{array}{l}\text { Jeffrey L. Dage, } \\
\text { PhD }\end{array}$ & $\begin{array}{l}\text { Eli Lilly and Company, } \\
\text { Indianapolis, IN }\end{array}$ & $\begin{array}{l}\text { Major role in the acquisition } \\
\text { of data; interpreted the data; } \\
\text { revised the manuscript for } \\
\text { intellectual content }\end{array}$ \\
$\begin{array}{l}\text { Oskar } \\
\text { Hansson, MD, } \\
\text { PhD }\end{array}$ & $\begin{array}{l}\text { Lund University, Malmö; } \\
\text { Lund, Sweden }\end{array}$ & $\begin{array}{l}\text { Designed and conceptualized } \\
\text { study; analyzed the data; } \\
\text { drafted the manuscript for } \\
\text { intellectual content }\end{array}$ \\
\hline
\end{tabular}

\section{References}

1. Grundke-Iqbal I, Iqbal K, Tung YC, Quinlan M, Wisniewski HM, Binder LI. Abnormal phosphorylation of the microtubule-associated protein tau (tau) in Alzheimer cytoskeletal pathology. Proc Natl Acad Sci USA. 1986;83(13): 4913-4917.

2. Petersen RC, Aisen P, Boeve BF, et al. Mild cognitive impairment due to Alzheimer disease in the community. Ann Neurol. 2013;74(2):199-208

3. Hansson O, Zetterberg H, Buchhave P, Londos E, Blennow K, Minthon L. Association between CSF biomarkers and incipient Alzheimer's disease in patients with mild cognitive impairment: a follow-up study. Lancet Neurol. 2006;5(3):228-234.

4. Skillback T, Farahmand T, Rosen C, et al. Cerebrospinal fluid tau and amyloid-beta142 in patients with dementia. Brain. 2015;138(pt 9):2716-2731.

5. Barthélemy NR, Fenaille F, Hirtz C, et al. Tau protein quantification in human cerebrospinal fluid by targeted mass spectrometry at high sequence coverage provides insights into its primary structure heterogeneity. J Proteome Res. 2016;15(9):667-676.

6. Cicognola C, Brinkmalm G, Wahlgren J, et al. Novel tau fragments in cerebrospinal fluid: relation to tangle pathology and cognitive decline in Alzheimer's disease. Acta Neuropathol. 2019;137(2):279-296.

7. Meredith JE Jr, Sankaranarayanan S, Guss V, et al. Characterization of novel CSF Tau and ptau biomarkers for Alzheimer's disease. PLoS One. 2013;8(10):e76523.

8. Sato C, Barthélemy NR, Mawuenyega KG, et al. Tau kinetics in neurons and the human central nervous system. Neuron. 2018;97(6):1284-1298.e7.

9. Goedert M, Wischik CM, Crowther RA, Walker JE, Klug A. Cloning and sequencing of the cDNA encoding a core protein of the paired helical filament of Alzheimer disease: identification as the microtubule-associated protein tau. Proc Natl Acad Sci USA. 1988;85(11):4051-4055.

10. Blennow K, Wallin A, Agren H, Spenger C, Siegfried J, Vanmechelen E. Tau protein in cerebrospinal fluid: a biochemical marker for axonal degeneration in Alzheimer disease? Mol Chem Neuropathol. 1995;26(3):231-245.

11. Vincent I, Zheng JH, Dickson DW, Kress Y, Davies P. Mitotic phosphoepitopes precede paired helical filaments in Alzheimer's disease. Neurobiol Aging. 1998;19(4:287-296.

12. Buerger K, Ewers M, Pirttilä T, et al. CSF phosphorylated tau protein correlates with neocortical neurofibrillary pathology in Alzheimer's disease. Brain. 2006;129(pt 11): 3035-3041.

13. Buerger K, Alafuzoff I, Ewers M, Pirttilä T, Zinkowski R, Hampel H. No correlation between CSF tau protein phosphorylated at threonine 181 with neocortical neurofibrillary pathology in Alzheimer's disease. Brain. 2007;130(pt 10):e82.

14. Janelidze S, Stomrud E, Smith R, et al. Cerebrospinal fluid p-tau217 performs better than p-tau181 as a biomarker of Alzheimer's disease. Nat Commun. 2020;11(1):1683.

15. Mattsson-Carlgren N, Andersson E, Janelidze S, et al. Abeta deposition is associated with increases in soluble and phosphorylated tau that precede a positive tau PET in Alzheimer's disease. Sci Adv. 2020;6(16):eaaz2387.

16. Barthélemy NR, Li Y, Joseph-Mathurin N, et al. A soluble phosphorylated tau signature links tau, amyloid and the evolution of stages of dominantly inherited Alzheimer's disease. Nat Med. 2020;26(3):398-407.

17. Jack CR Jr, Bennett DA, Blennow K, et al. NIA-AA Research Framework: toward a biological definition of Alzheimer's disease. Alzheimers Dement. 2018;14(4):535-562.

18. Wesseling H, Mair W, Kumar M, et al. Tau PTM profiles identify patient heterogeneity and stages of Alzheimer's disease. Cell. 2020;183(6):1699-1713.e13.

19. American Psychiatric Association. Diagnostic and Statistical Manual of Mental Disorders: DSM-5. American Psychiatric Association; 2013.

20. Armstrong MJ, Litvan I, Lang AE, et al. Criteria for the diagnosis of corticobasal degeneration. Neurology. 2013;80(5):496-503.

21. Höglinger GU, Respondek G, Stamelou M, et al. Clinical diagnosis of progressive supranuclear palsy: the Movement Disorder Society criteria. Mov Disord. 2017;32(6): 853-864.

22. Postuma RB, Berg D, Adler $\mathrm{CH}$, et al. The new definition and diagnostic criteria of Parkinson's disease. Lancet Neurol. 2016;15(6):546-548.

23. Rascovsky K, Hodges JR, Knopman D, et al. Sensitivity of revised diagnostic criteria for the behavioural variant of frontotemporal dementia. Brain. 2011;134(pt 9): 2456-2477.

24. Román GC, Tatemichi TK, Erkinjuntti T, et al. Vascular dementia: diagnostic criteria for research studies: report of the NINDS-AIREN International Workshop. Neurology. 1993;43(2):250-260. 
25. Leuzy A, Smith R, Ossenkoppele R, et al. Diagnostic performance of RO948 F 18 tau positron emission tomography in the differentiation of Alzheimer disease from other neurodegenerative disorders. JAMA Neurol. 2020;77(8):955-965.

26. Hansson O, Seibyl J, Stomrud E, et al. CSF biomarkers of Alzheimer's disease concord with amyloid-beta PET and predict clinical progression: a study of fully automated immunoassays in BioFINDER and ADNI cohorts. Alzheimers Dement. 2018;14(11):1470-1481.

27. Smith R, Scholl M, Leuzy A, et al. Head-to-head comparison of tau positron emission tomography tracers [F]flortaucipir and [F]RO948. Eur J Nucl Med Mol Imaging. 2020;47: 342-354.

28. Palmqvist S, Zetterberg H, Blennow $\mathrm{K}$, et al. Accuracy of brain amyloid detection in clinical practice using cerebrospinal fluid beta-amyloid 42: a cross-validation study against amyloid positron emission tomography. JAMA Neurol. 2014;71(10):1282-1289.

29. Lundqvist R, Lilja J, Thomas BA, et al. Implementation and validation of an adaptive template registration method for $18 \mathrm{~F}$-flutemetamol imaging data. J Nucl Med. 2013; 54(8):1472-1478

30. Jack CR Jr, Wiste HJ, Weigand SD, et al. Defining imaging biomarker cut points for brain aging and Alzheimer's disease. Alzheimers Dement. 2017;13(3):205-216.

31. Cho H, Choi JY, Hwang MS, et al. In vivo cortical spreading pattern of tau and amyloid in the Alzheimer disease spectrum. Ann Neurol. 2016;80(2):247-258.

32. Diedenhofen B, Musch J. cocor: A comprehensive solution for the statistical comparison of correlations. PLoS One. 2015;10(3):e0121945.

33. DeLong ER, DeLong DM, Clarke-Pearson DL. Comparing the areas under two or more correlated receiver operating characteristic curves: a nonparametric approach. Biometrics. 1988;44(3):837-845.

34. Barthélemy NR, Mallipeddi N, Moiseyev P, Sato C, Bateman RJ. Tau phosphorylation rates measured by mass spectrometry differ in the intracellular brain vs. extracellular cerebrospinal fluid compartments and are differentially affected by Alzheimer's disease. Front Aging Neurosci. 2019;11:121.

35. Barthelemy NR, Bateman R, Marin P, et al. Tau hyperphosphorylation on T217 in cerebrospinal fluid is specifically associated to amyloid- $\beta$ pathology. BioRxiv. Epub 2017 Nov 30 .

36. Medina M, Avila J. Further understanding of tau phosphorylation: implications for therapy. Expert Rev Neurother. 2015;15(1):115-122.

37. Olsson B, Lautner R, Andreasson U, et al. CSF and blood biomarkers for the diagnosis of Alzheimer's disease: a systematic review and meta-analysis. Lancet Neurol. 2016;15: 673-684.
38. Yanamandra K, Patel TK, Jiang H, et al. Anti-tau antibody administration increases plasma tau in transgenic mice and patients with tauopathy. Sci Transl Med. 2017; 9(386): eaal2029.

39. McDade E, Wang G, Gordon BA, et al. Longitudinal cognitive and biomarker changes in dominantly inherited Alzheimer disease. Neurology. 2018;91(14):e1295-e1306.

40. Braak H, Del Tredici K. Amyloid-beta may be released from non-junctional varicosities of axons generated from abnormal tau-containing brainstem nuclei in sporadic Alzheimer's disease: a hypothesis. Acta Neuropathol. 2013;126(2):303-306.

41. Hardy J, Allsop D. Amyloid deposition as the central event in the aetiology of Alz heimer's disease. Trends Pharmacol Sci. 1991;12(10):383-388.

42. Suárez-Calvet M, Karikari TK, Ashton NJ, et al. Novel tau biomarkers phosphorylated at T181, T217 or T231 rise in the initial stages of the preclinical Alzheimer's continuum when only subtle changes in Abeta pathology are detected. EMBO Mol Med. 2020;12(12):e12921.

43. Karikari TK, Emersic A, Vrillon A, et al. Head-to-head comparison of clinical performance of CSF phospho-tau T181 and T217 biomarkers for Alzheimer's disease diagnosis. Alzheimers Dement. 2020:17(5):755-767.

44. Mair W, Muntel J, Tepper K, et al. FLEXITau: quantifying post-translational modifications of tau protein in vitro and in human disease. Anal Chem. 2016;88(7) 3704-3714.

45. Horie K, Barthélemy NR, Mallipeddi N, et al. Regional correlation of biochemical measures of amyloid and tau phosphorylation in the brain. Acta Neuropathol Commun. 2020;8(1):149.

46. Kanmert D, Cantlon A, Muratore CR, et al. C-terminally truncated forms of tau, but not full-length tau or its C-terminal fragments, are released from neurons in dependently of cell death. J Neurosci. 2015;35(30):10851-10865.

47. Villemagne VL, Pike KE, Chetelat G, et al. Longitudinal assessment of Abeta and cognition in aging and Alzheimer disease. Ann Neurol. 2011;69(1):181-192.

48. Rullmann M, McLeod A, Grothe M, Sabri O, Barthel H. Reshaping the amyloid buildup curve in Alzheimer's disease? - partial volume effect correction of longitudinal amyloid PET data. J Nucl Med. 2020;61(12):1820-1824.

49. Blennow K, Mattsson N, Schöll M, Hansson O, Zetterberg H. Amyloid biomarkers in Alzheimer's disease. Trends Pharmacol Sci. 2015;36(5):297-309.

50. Blennow K, Hampel H. CSF markers for incipient Alzheimer's disease. Lancet Neurol. 2003;2(10):605-613. 


\section{Neurology}

\section{Comparing the Clinical Utility and Diagnostic Performance of CSF P-Tau181, P-Tau217, and P-Tau231 Assays}

Antoine Leuzy, Shorena Janelidze, Niklas Mattsson-Carlgren, et al.

Neurology 2021;97;e1681-e1694 Published Online before print September 7, 2021

DOI 10.1212/WNL.0000000000012727

This information is current as of September 7, 2021

\section{Updated Information \&} Services

References

Citations

Subspecialty Collections

Permissions \& Licensing

Reprints including high resolution figures, can be found at: http://n.neurology.org/content/97/17/e1681.full

This article cites 48 articles, 10 of which you can access for free at: http://n.neurology.org/content/97/17/e1681.full\#ref-list-1

This article has been cited by 4 HighWire-hosted articles: http://n.neurology.org/content/97/17/e1681.full\#\#otherarticles

This article, along with others on similar topics, appears in the following collection(s):

Alzheimer's disease

http://n.neurology.org/cgi/collection/alzheimers_disease

Cerebrospinal Fluid

http://n.neurology.org/cgi/collection/cerebrospinal_fluid

Class II

http://n.neurology.org/cgi/collection/class_ii

PET

http://n.neurology.org/cgi/collection/pet

Information about reproducing this article in parts (figures,tables) or in its entirety can be found online at:

http://www.neurology.org/about/about_the_journal\#permissions

Information about ordering reprints can be found online:

http://n.neurology.org/subscribers/advertise

Neurology ${ }^{\circledR}$ is the official journal of the American Academy of Neurology. Published continuously since 1951, it is now a weekly with 48 issues per year. Copyright Copyright ( 2021 The Author(s). Published by Wolters Kluwer Health, Inc. on behalf of the American Academy of Neurology.. All rights reserved. Print ISSN: 0028-3878. Online ISSN: 1526-632X.

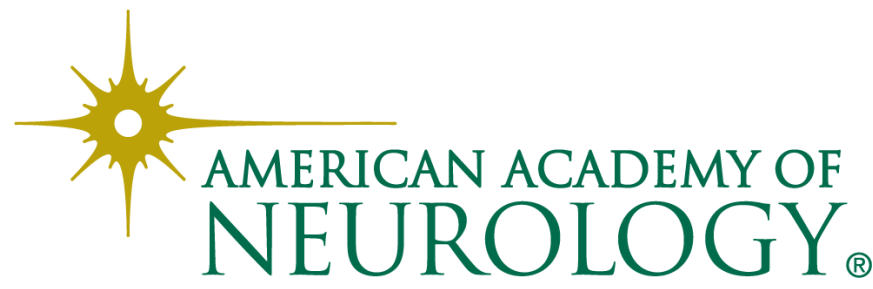

